Prepared for the U.S. Department of Energy

under Contract DE-AC05-76RL01830

\title{
Simulant Development for Hanford Tank Farms Double Valve Isolation (DVI) Valves Testing
}

Report to Washington River Protection Solutions to be released as RPP-RPT-54347

BE Wells

January 2013

Pacific Northwest

NATIONAL LABORATORY

Proudly Operated by Battelle Since 1965 


\title{
DISCLAIMER
}

This report was prepared as an account of work sponsored by an agency of the United States Government. Neither the United States Government nor any agency thereof, nor Battelle Memorial Institute, nor any of their employees, makes any warranty, express or implied, or assumes any legal liability or responsibility for the accuracy, completeness, or usefulness of any information, apparatus, product, or process disclosed, or represents that its use would not infringe privately owned rights. Reference herein to any specific commercial product, process, or service by trade name, trademark, manufacturer, or otherwise does not necessarily constitute or imply its endorsement, recommendation, or favoring by the United States Government or any agency thereof, or Battelle Memorial Institute. The views and opinions of authors expressed herein do not necessarily state or reflect those of the United States Government or any agency thereof.

\author{
PACIFIC NORTHWEST NATIONAL LABORATORY \\ operated by \\ BATTELLE \\ for the \\ UNITED STATES DEPARTMENT OF ENERGY \\ under Contract DE-AC05-76RL01830
}

Printed in the United States of America
Available to DOE and DOE contractors from the Office of Scientific and Technical Information, P.O. Box 62, Oak Ridge, TN 37831-0062; ph: (865) 576-8401 fax: $(865) 576-5728$
email: reports@adonis.osti.gov
Available to the public from the National Technical Information Service 5301 Shawnee Rd., Alexandria, VA 22312 ph: (800) 553-NTIS (6847) email: orders $a$ ntis.gov $<$ http://www.ntis.gov/about/form.aspx> Online ordering: http://www.ntis.gov


PNNL-22121

DVI-RPT-0001, Rev. 0

\section{Simulant Development for Hanford Tank Farms Double Valve Isolation (DVI) Valves Testing}

Report to Washington River Protection Solutions to be released as RPP-RPT-54347

BE Wells

January 2013

Prepared for

the U.S. Department of Energy

under Contract DE-AC05-76RL01830

Pacific Northwest National Laboratory

Richland, Washington 99352 



\section{Summary}

Leakage testing of a representative sample of the safety-significant isolation valves for Double Valve Isolation (DVI) in an environment that simulates the abrasive characteristics of the Hanford Tank Farms Waste Transfer System during waste feed delivery to the Waste Treatment and Immobilization Plant (WTP) is to be conducted. The testing will consist of periodic leak evaluations performed on the DVI valves after prescribed numbers of valve cycles (open and close) in a simulated environment representative of the abrasive properties of the waste and the Waste Transfer System. The valve operations include exposure to cycling conditions that include gravity drain and flush operation following slurry transfer. The simulant test will establish the performance characteristics and verify compliance with the Documented Safety Analysis. Proper simulant development is essential to ensure that the critical process streams characteristics are represented according to the National Research Council (NRC) report, Advice on the Department of Energy's Cleanup Technology Roadmap: Gaps and Bridges (NRC 2009).

A basis for evaluating DVI test simulants relative to Hanford Site waste has been defined based on 10 metrics that represent the primary phenomenon describing valve surface physical abrasion due to particle interaction as well as secondary metrics for pipeline transfer and erosion as the slurry is flowing through the piping, particle settling under conditions of no flow, and particle suspension for conditions of re-establishing flow as described below. The different metrics are considered because the dependence of these metrics on particle characteristics are different, and include:

1-5. Valve surface relative abrasive wear rate for stainless steel, nickel plating, Tefzel ${ }^{\circledR},{ }^{1} \mathrm{Kynar}^{\circledR},{ }^{2}$ and ultra-high molecular-weight-polyethylene (UHMWPE)

6. Pipeline critical transport velocity

7. Pipeline erosion rate

8. Archimedes number

9. Settling velocity

10. Critical shear stress for erosion of noncohesive particles.

Characterizations of the simulant and waste particles with respect to particle size, density and hardness, and valve surface hardness are described. Comparison of the Washington River Protection Solutions prescribed DVI valve testing simulant relative to Hanford waste showed that the simulant is generally similar for up to $80 \%$ by volume of the composite waste characterization for metrics related to pipeline erosion, but it is not challenging with respect to DVI valve abrasive wear. As a result, an adjusted simulant was developed that matched the $75^{\text {th }}$ percentile by waste undissolved solid volume of the metrics.

Components and concentrations for an alternative DVI valve testing simulant were selected from components of the prescribed DVI valve testing simulant, a simulant used for the Tank Operations Contractor Waste Feed Delivery Mixing and Sampling Program tank performance testing, and a WTP simulant. As some of prescribed DVI valve testing simulant components were no longer available, replacement components with similar characteristics were selected. The recommended simulant, Table S.1, represents the $75^{\text {th }}$ percentile by volume of characterized Hanford waste particulate based on

\footnotetext{
${ }^{1}$ Tefzel is a registered trademark of E.I. du Pont de Nemours and Company, Wilmington, Delaware.

${ }^{2}$ Kynar is a registered trademark of Arkema Inc., Philadelphia, Pennsylvania.
} 
the comparison metrics with the valve abrasive metrics given highest priority. The recommended simulant qualitatively matches or is more challenging than the $75^{\text {th }}$ percentile by volume waste target, and the simulant development took into account the cost and availability of potential components. The component characteristics are representative of Hanford waste particulate.

Table S.1. Recommended DVI Valve Test Simulant

\begin{tabular}{|c|c|c|c|c|c|c|c|}
\hline \multirow[b]{2}{*}{ Component } & \multirow{2}{*}{$\begin{array}{l}\text { Crystal } \\
\text { Density } \\
(\mathrm{g} / \mathrm{mL})\end{array}$} & \multirow{2}{*}{$\begin{array}{c}\text { Mohs } \\
\text { Hardness }\end{array}$} & \multirow{2}{*}{$\begin{array}{l}\text { Volume } \\
\text { Fraction }\end{array}$} & \multirow{2}{*}{$\begin{array}{l}\text { Mass } \\
\text { Fraction }\end{array}$} & \multicolumn{3}{|c|}{$\begin{array}{c}\text { Approximate Percentile } \\
\text { Particle Size }(\mu \mathrm{m})\end{array}$} \\
\hline & & & & & $1^{\text {st }}$ & $50^{\text {th }}$ & $90^{\text {th }}$ \\
\hline Gibbsite & 2.42 & 3 & 0.24 & 0.186 & 7.4 & 80 & 158 \\
\hline Zeolite & 2.15 & 3.75 & 0.18 & 0.124 & 4.7 & 53 & 309 \\
\hline $\mathrm{Ca}_{5} \mathrm{OH}\left(\mathrm{PO}_{4}\right)_{3}$ & 3.14 & 5 & 0.12 & 0.120 & 1.0 & 4.7 & 12 \\
\hline $\mathrm{Bi}_{2} \mathrm{O}_{3}$ & 8.9 & 4.5 & 0.02 & 0.057 & 2.6 & 8.7 & 24 \\
\hline Boehmite & 3.01 & 4 & 0.22 & 0.212 & 2.2 & 8.5 & 21 \\
\hline Large Gibbsite & 2.42 & 3.4 & 0.08 & 0.062 & 0.3 & 8.8 & 20 \\
\hline Large Sand & 2.65 & 6.5 & 0.03 & 0.025 & 133 & 394 & 592 \\
\hline $\begin{array}{l}\text { Zirconium } \\
\text { Oxide }\end{array}$ & 5.7 & 8 & 0.09 & 0.164 & 0.4 & 13 & 30 \\
\hline Stainless Steel & 8 & 5.5 & 0.02 & 0.051 & 4.5 & 59 & 152 \\
\hline
\end{tabular}




\section{Acknowledgments}

The author thanks CW Enderlin for his independent technical review, SA Suffield for her calculation review, and KR Neiderhiser for the technical editing. 



\section{Acronyms and Abbreviations}

$\mathrm{Ar}$

CFR

DOE

DSA

DVI

PBM

PNNL

PSDD

SSMD

UDS

UHMWPE

VHN

WRPS

WTP
Archimedes number

Code of Federal Regulations

U.S. Department of Energy

Documented Safety Analysis

Double Valve Isolation

Pittsburgh Brass Manufacturing

Pacific Northwest National Laboratory

particle size and density distribution

Small Scale Mixing Demonstration

undissolved solids

ultra-high molecular-weight polyethylene

Vickers Hardness Number

Washington River Protection Solutions LLC

Waste Treatment and Immobilization Plant 



\section{Contents}

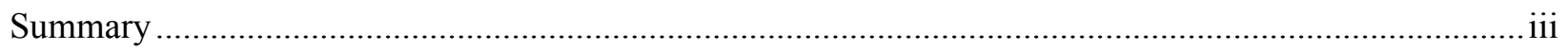

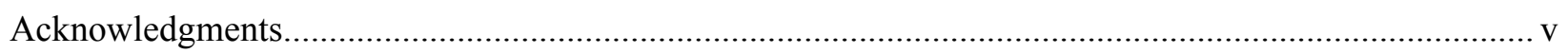

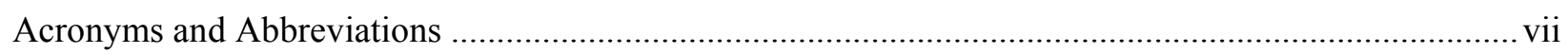

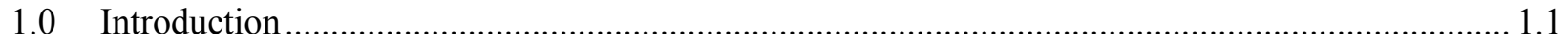

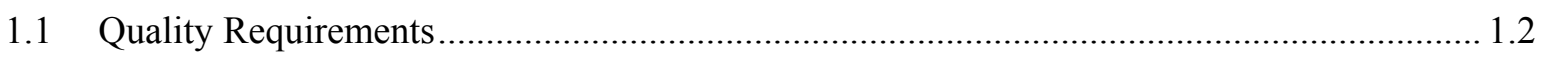

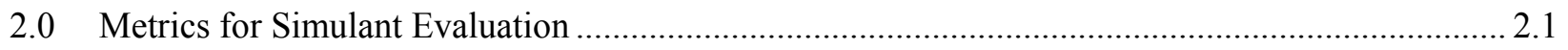

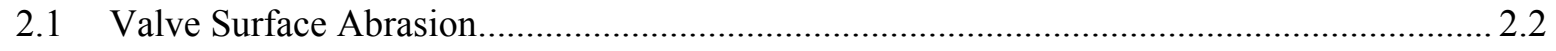

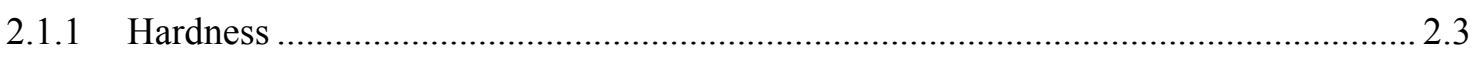

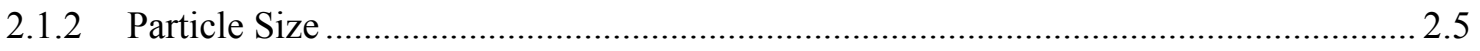

2.1.3 Particle Shape and Surface Characteristics............................................................ 2.6

2.1.4 Valve Surface Abrasion Summary ................................................................... 2.7

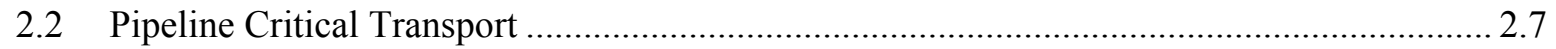

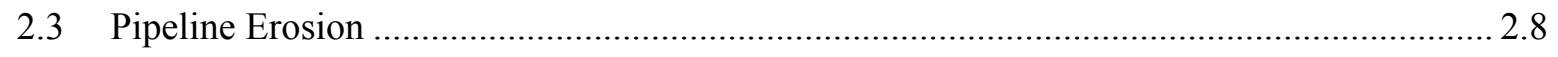

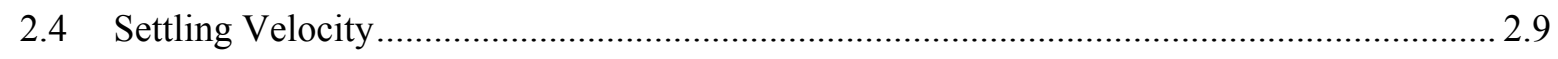

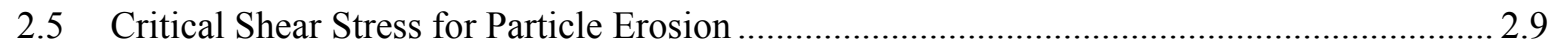

3.0 DVI Valve Surface and Particle Properties ............................................................................. 3.1

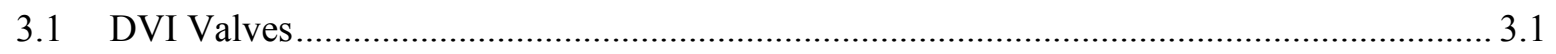

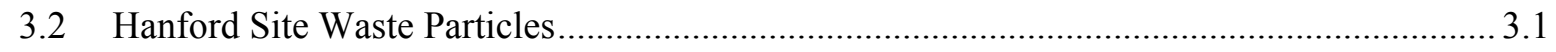

3.3 RPP-PLAN-44556, Rev. 2, Simulant Particles .................................................................... 3.4

4.0 Comparison of Hanford Waste and Simulants ......................................................................... 4.1

4.1 RPP-PLAN-44556, Rev. 2, Simulant Comparison .............................................................. 4.1

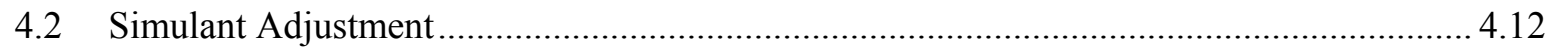

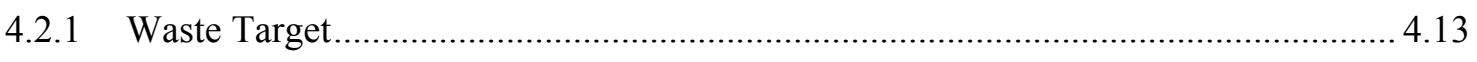

4.2.2 Adjusted Simulant to Represent Waste Target ...................................................... 4.13

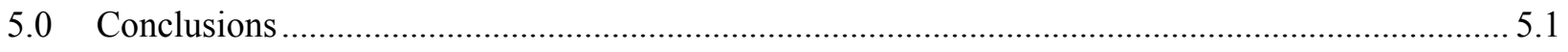

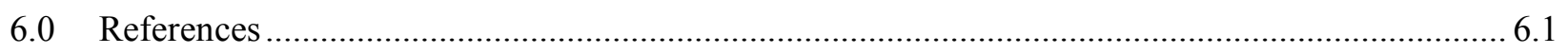




\section{Figures}

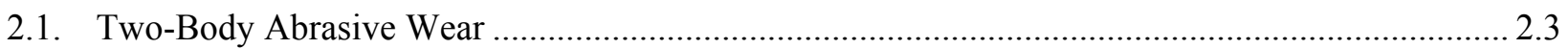

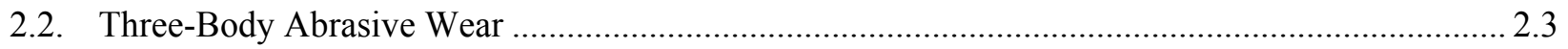

2.3. Relative Abrasive Wear Resistance as a Function of Hardness Ratio ......................................... 2.4

2.4. Relative Abrasive Wear Rate as a Function of Hardness Ratio ...................................................... 2.5

2.5. Particle-Size Effect in Two-Body Abrasion.............................................................................. 2.6

4.1. Tefzel ${ }^{\circledR}$ Valve Seat Reference Wear Rate Comparison................................................................ 4.2

4.2. Kynar $^{\circledR}$ Valve Seat Reference Wear Rate Comparison................................................................. 4.3

4.3. UHMWPE Valve Seat Reference Wear Rate Comparison........................................................ 4.4

4.4. Stainless Steel Valve Ball Reference Wear Rate Comparison...................................................... 4.5

4.5. Nickel Plating Valve Ball Reference Wear Rate Comparison...................................................... 4.6

4.6. Pipeline Critical Transport Velocity Comparison ..................................................................... 4.7

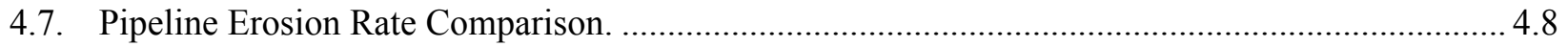

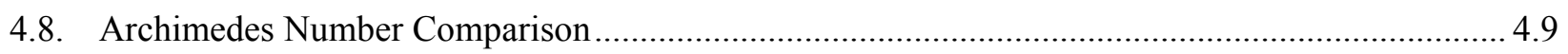

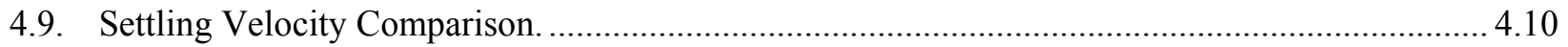

4.10. Critical Shear Stress for Erosion of Non-Cohesive Particles Comparison................................... 4.11

4.11. Tefzel ${ }^{\circledR}$ Valve Seat Reference Wear Rate Comparison............................................................. 4.17

4.12. Kynar $^{\circledR}$ Valve Seat Reference Wear Rate Comparison.............................................................. 4.18

4.13. UHMWPE Valve Seat Reference Wear Rate Comparison........................................................ 4.19

4.14. Stainless Steel Valve Ball Reference Wear Rate Comparison..................................................... 4.20

4.15. Nickel Plating Valve Ball Reference Wear Rate Comparison................................................... 4.21

4.16. Pipeline Critical Transport Velocity Comparison ..................................................................... 4.22

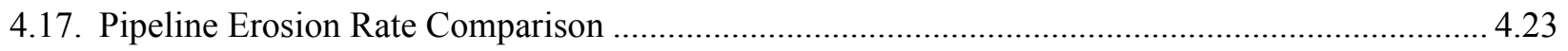

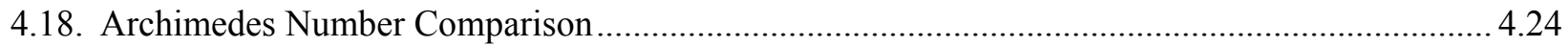

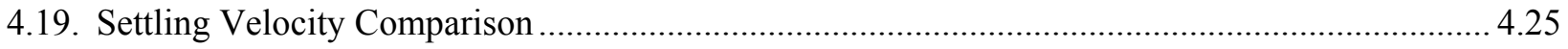

4.20. Critical Shear Stress for Erosion of Non-Cohesive Particles Comparison................................... 4.26

\section{Tables}

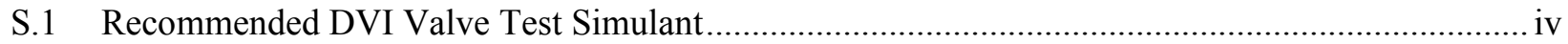

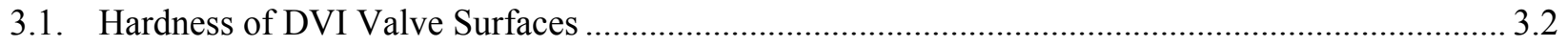

3.2. Hanford Sludge Non-Salt Particle Hardness ......................................................................... 3.3

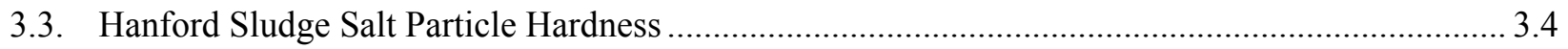

3.4. RPP-PLAN-44556, Rev. 2 DVI Valve Test Simulant ............................................................. 3.5

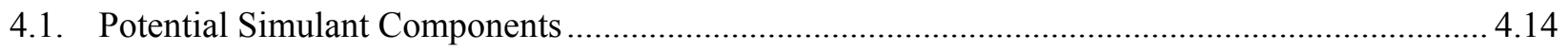

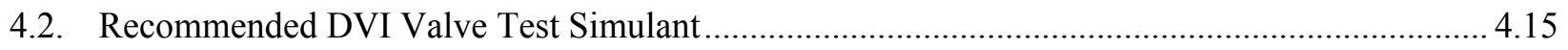

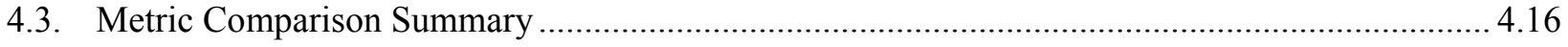




\subsection{Introduction}

As specified in RPP-PLAN-44556, Rev. 2, leakage testing of a representative sample of the safety-significant isolation valves for Double Valve Isolation (DVI) in an environment that simulates the abrasive characteristics of the Hanford Tank Farms Waste Transfer System during waste feed delivery to the Waste Treatment and Immobilization Plant (WTP) is to be conducted. This testing is to address the issue recognized in RPP-RPT-41859, Rev. 0, that valve seat exposure to abrasive particles in the waste can limit valve life.

RPP-RPT-41859, Rev. 0, examined the failure modes of DVI valves as a result of the waste transfer process operating conditions including exposure to corrosion, erosion, radiation fields, system operating pressures, and temperatures, and issues related to aging, structural loading, external events, external environmental conditions, and other failure modes. The materials of the DVI valve bodies, valve balls, and valve seats are chemically and radiologically resistant to the transferred waste, and are acceptable for the temperatures and pressures expected in waste transfer operations. Based on manufacturer's data, the seat materials were selected to be abrasion resistant. However, the testing of these valves in the fluids representative of the transferred waste has not been performed. The RPP-RPT-41859, Rev. 0, evaluation concluded that the materials used for the DVI valves provide adequate capability to withstand the postulated failure modes due to operation in the Waste Transfer System but, as referenced above, valve life can be limited by valve seat exposure to abrasive particles in the waste.

Waste Transfer System DVI valve cycles (open and close) are estimated to amount to no more than 500 cycles during the life expectancy of the valves. The safety function of the safety-significant valves is to limit leakage of waste in order to decrease the consequences of a fine spray leak due to a transfer misroute (RPP-PLAN-44556, Rev. 2). Preventing a misroute also protects facility workers from wetting spray/jet/stream leaks into a normally occupied area, which could result in flammable gas deflagrations in a waste transfer associated structure. The DVIs also provide a barrier to physically disconnect interfacing systems and inactive portions of waste transfer primary piping from an active portion of the Waste Transfer System.

The purpose of the RPP-PLAN-44556, Rev. 2, simulant test is to leak test representative samples of the currently used DVI valves in a simulated environment representative of the abrasive properties of the waste and Waste Transfer System operating and cycling conditions. The valve operations include exposure to cycling conditions that include gravity drain and flush operation following slurry transfer. The simulant test will establish the performance characteristics and verify compliance with the Documented Safety Analysis (DSA).

As pointed out in the National Research Council (NRC) report, Advice on the Department of Energy's Cleanup Technology Roadmap: Gaps and Bridges (NRC 2009), testing with a complete range of actual radioactive wastes to cover all process limits in regard to chemical, physical, and rheological properties would require too much actual waste that is difficult to retrieve and handle; increases radiological safety hazards to laboratory staff; and in most cases, is too time consuming and costly. Simulated wastes can be developed to exhibit only a limited set of important properties for a specific application, or may be tailored to exhibit a broader range of chemical, physical, and rheological properties for a wide range of tests. Regardless, proper simulant development is essential to ensure that the critical radioactive process streams characteristics are represented. 
The benefits of developing accurate and reliable waste slurry simulants are discussed in NRC (2009):

"The absence of adequate understanding of the behavior of process streams can necessitate overly conservative and costly process designs to minimize the risk of a process failure or the risk of unrecognized safety issues, which as a worst case can render a facility inoperable with the actual radioactive waste it was intended to process."

This report describes the basis for evaluating the solid particles of the DVI simulant specified in RPP-PLAN-44556, Rev. 2, relative to Hanford Site waste and, based on the outcome of that evaluation, defines an alternative simulant representative of a specific target of the characterized Hanford waste from that basis. The simulant evaluation approach is similar to the comparison of the simulant used in Washington River Protection Solutions' (WRPS) Small Scale Mixing Demonstration (SSMD) small-scale mixing tests to Hanford waste (Wells et al. 2012) and simulant definition for the Tank Operations Contractor Waste Feed Delivery Mixing and Sampling Program tank performance testing (Lee et al. 2012).

Metrics considered for the DVI simulant evaluation are described in Section 2. The pertinent DVI valve components, Hanford waste characterizations employed for comparison, and the RPP-PLAN-44556, Rev. 2, simulant are summarized in Section 3, and the comparison results, together with an alternative simulant representative of a specific waste target with potential simulant component candidates, are presented in Section 4. Conclusions are provided in Section 5, and references are listed in Section 6.

\subsection{Quality Requirements}

The leakage testing of a representative sample of the safety-significant isolation valves for DVI is required to comply with all NQA-1 requirements and quality clauses as specified in the SOW and RPP-PLAN-44556, Rev. 2.

The Pacific Northwest National Laboratory (PNNL) Quality Assurance Program is based upon the requirements as defined in the U.S. Department of Energy (DOE) Order 414.1D, Quality Assurance and 10 CFR 830, Energy/Nuclear Safety Management, Subpart A - Quality Assurance Requirements (a.k.a. the Quality Rule). PNNL has chosen to implement the following consensus standards in a graded approach:

- ASME NQA-1-2000, Quality Assurance Requirements for Nuclear Facility Applications, Part 1, Requirements for Quality Assurance Programs for Nuclear Facilities.

- ASME NQA-1-2000, Part II, Subpart 2.7, Quality Assurance Requirements for Computer Software for Nuclear Facility Applications.

- ASME NQA-1-2000, Part IV, Subpart 4.2, Graded Approach Application of Quality Assurance Requirements for Research and Development.

The procedures necessary to implement the requirements are documented through PNNL's "How Do I...? (HDI).

The work contained herein was performed utilizing the WTPSP project Quality Assurance Program, an NQA-1-2000 Quality Assurance Program, graded on the approach presented in NQA-1-2000, Part IV, 
Subpart 4.2, implemented in accordance with QA-WTPSP-0001, The WTPSP Quality Assurance Plan, and 62598-QA-001, DVI Tank Waste Simulant Test Project Quality Assurance Plan. ${ }^{1}$

${ }^{1}$ 62598-QA-001, Rev. 0, 2012, DVI Tank Waste Simulant Test Project Quality Assurance Plan, Pacific Northwest National Laboratory, Richland, WA. 



\subsection{Metrics for Simulant Evaluation}

The simulant evaluation builds upon the comparison approach of the simulant used in WRPS' SSMD small-scale mixing tests to Hanford Site waste (Wells et al. 2012) and simulant definition for the Tank Operations Contractor Waste Feed Delivery Mixing and Sampling Program tank performance testing (Lee et al. 2012). In these evaluations, the solid particles of the simulants are compared to waste particles characterization using performance metrics related to the waste feed delivery environment from the literature.

Lee et al. (2012) described previous studies that have demonstrated that the mixing and transfer performance in the tank farm waste feed delivery system depends on the distribution of solid particle sizes and densities, and it is expected that the performance for transferring any specific, rapidly settling particle will depend on overall size and density distribution of the particulate in the simulant. For slurries that have particle sizes and densities that vary, a useful method to compare different slurries is to calculate a performance metric that combines the effect of size and density. However, different performance metrics can have different functionalities with particle size and density. The comparison of one metric may thus be different than a comparison based on a different metric.

As examples of different performance metric functionalities, the dependence of particle size (d) and density (S, ratio of solid to liquid density) of two metrics used in both (Wells et al. 2012) and (Lee et al. 2012) are described. The Archimedes number, Ar, and the jet velocity needed to achieve a certain degree of solid suspension, $U_{n}$, have functionalities of $\operatorname{Ar} \rightarrow(S-1) d^{3}$ and $U_{n} \rightarrow(S-1)^{0.38} d^{0.14}$. Thus, a distribution of different size and density solid particles can compare differently to another solid particle distribution depending on which metric is considered. An approach considering both metrics at the same time provides demonstration that the simulant is representative for both metrics.

Lee et al. (2012) therefore determined conceptual solid particle simulants using a set of metrics addressing the different functionalities of particle size and density for mobilization, suspension, settling, and pipeline transfer. Adjustment of potential simulant components and concentrations is made such that the calculated simulant and the waste targets for the majority of the metrics are similar. In some instances, different particle size distributions of the same component are required to match the range of metric results for the waste target. The weighted average density of the particulate relative to the target waste is also considered.

The DVI valves used in the Waste Transfer System are installed in shop-fabricated jumper assemblies before they are installed onsite. The jumpers with the DVI valves in the Waste Transfer System are located within below-grade concrete pits or aboveground, steel portable valve boxes. From RPP-PLAN-44556, Rev. 2, the test equipment therefore includes:

- An electric motor-driven centrifugal pump

- 3-inch piping either horizontal or slightly sloped with long radius elbows

- Valves mounted in horizontal runs with the stem up in a test manifold that is capable of testing multiple valves at a time.

With these prototypic and testing configurations, the bases for selecting the solid particles of the DVI slurry simulant are, therefore, the primary metrics describing valve surface abrasion due to particle 
interaction as well as secondary metrics for pipeline transfer and erosion as the slurry is flowing through the piping, particle settling under conditions of no flow, and particle suspension for conditions of re-establishing flow as described below. The different metrics are considered because the dependence of these metrics on particle characteristics are different. As previously described, evaluation of the different metrics is made because it may be that a simulant that is representative or challenging for one aspect of the DVI testing system may not be so for some other aspect of that system.

Also, the comparison of the performance of the simulant and waste particles as defined by the metrics is determined on a particle-by-particle basis, and not as the performance of the composite mixture. This approach is followed due to the lack of bases for the performance of the composites as defined by the metrics. An example of the effect of composite mixtures is provided in Lee et al. (2012).

Following the approach of Wells et al. (2012) and Lee et al. (2012), the performance metric models are selected as examples and may not address certain aspects of the Hanford waste. Other selected models may not encompass the size and density ranges of the waste and simulant, or may not be directly applicable to the DVI valve testing configurations. These model choices are necessitated by the lack of specific models for the current evaluation. Additionally, as specified in Section 1, the objective of the DVI valve testing is to perform leakage testing of a representative sample of the safety-significant isolation valves for DVI in an environment that simulates the abrasive characteristics of the Hanford Tank Farms Waste Transfer System during waste feed delivery to the WTP. The selected metric models may not be directly related to test parameters for leakage, but are phenomena that occur in the waste feed system. Thus, it is the comparison of the model results for the waste and simulant particulates that is of significance, not the specific model results themselves.

\subsection{Valve Surface Abrasion}

Solid particles that are entrained into the valve body may abrade the valve contact surfaces, potentially creating a leak path within the valve. Physical abrasive wear is caused by loaded contact between a solid particle and a solid material wherein material is lost from the solid material by the passage of a hard particle over its surface (Stachowiak and Batchelor 2005).

The literature defines two basic modes of abrasive wear: 1) two body and 2) three body. In two-body abrasive wear, solid particles (grit) pass over the surface rigidly held as for a cutting tool (e.g., sandpaper as depicted in Figure 2.1). The particles are not held rigidly in three-body abrasive wear, and are thus free to roll and slide over the surface (Figure 2.2). Stachowiak and Batchelor (2005) note that three-body abrasive wear has been found to be 10 times slower than two-body wear due to the other wear mechanisms present in three-body wear. The focus of this current evaluation is two-body wear, wherein abrasive particles introduced in between the ball and seat of the DVI valves may imbed into the softer of these surfaces and cause wear on the opposing surface (e.g., Dwyer-Joyce et al. 1994).

A standard measure of the relative abrasivity of a slurry is the Miller Number or abrasivity index. As summarized in ASTM G75-07, the Miller Number is determined by measuring the mass loss of a standard-shaped $27 \%$ chrome iron metal wear block. In a reciprocating motion, the block is directly loaded onto fresh slurry supported on a sheet of Neoprene. ${ }^{1}$ A Miller Number can thus be deemed

\footnotetext{
${ }^{1}$ Neoprene is a registered trademark of E.I. du Pont de Nemours and Co., Wilmington, Delaware.
} 
representative of two-body abrasive wear, and the measurement includes all the associated mechanisms thereof with respect to the particle properties.

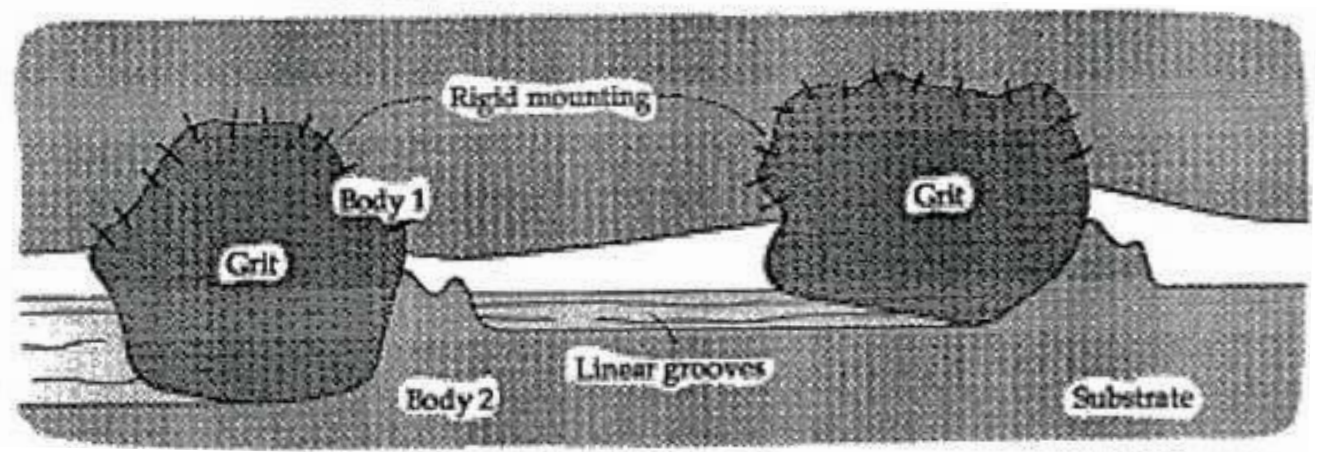

Figure 2.1. Two-Body Abrasive Wear (from Stachowiak and Batchelor 2005)
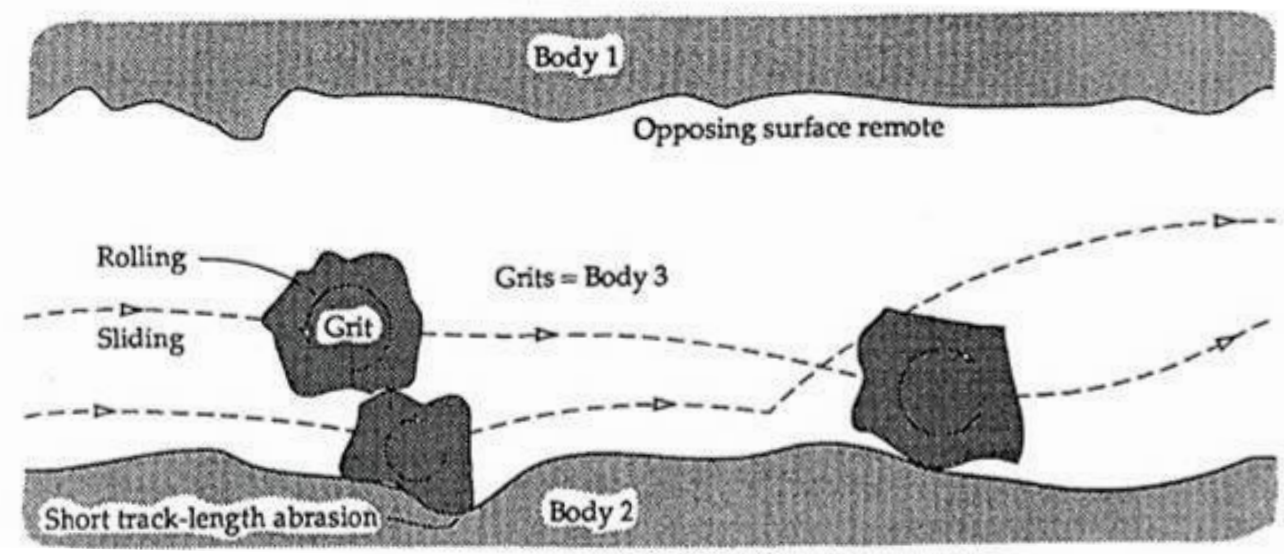

Figure 2.2. Three-Body Abrasive Wear (from Stachowiak and Batchelor 2005)

Miller Numbers have been established for a wide range of slurries (Jacobs 2005). However, no quantification for Hanford waste slurries has been identified. Thus, to relate potential simulant components and compositions to Hanford waste the particle properties contributing to abrasive wear are considered. Jacobs (2005) notes that, as described above for the Miller Number, most abrasivity data are obtained from laboratory simulation tests, and the interaction between the various factors involved make it very difficult to isolate the effects of the particle properties. The data can usually, therefore, be applied in fairly general or comparative terms only. Discussions of particle properties on the rates of abrasive wear of a surface, including particle hardness, size, shape, and surface roughness are provided below.

\subsubsection{Hardness}

The literature defines abrasive wear as the wear that occurs when a solid particle has nominally equal or greater hardness than a surface. However, little or no quantitative information is available on the direct effect of hardness (Jacobs 2005). In most instances, the hardness of the surface must be less than 0.8 of the particle hardness for rapid abrasion to occur. It has been observed, however, that a limited amount of abrasive wear still occurs to the surface if the yield stress of the surface exceeds that of the abrasive particles (Richardson 1967). 
Stachowiak and Batchelor (2005) provide a conceptual relation of relative wear resistance (wear resistance is the reciprocal of the wear rate) to the ratio of the surface or substrate hardness and the particle or abrasive hardness (Figure 2.3). The units of hardness are Vickers Hardness Number (VHN). The relative wear resistance is defined as the reciprocal of the surface wear rate divided by the reciprocal wear rate of a control or reference material. As the hardness of the abrasive particle increases relative to the surface, the relative wear resistance decreases. To restate, as depicted in Figure 2.4, as the hardness of the abrasive particle increases, the wear rate increases. The diamonds in Figure 2.4 depict data points taken from the Stachowiak and Batchelor (2005) relation of Figure 2.3, and a fit to this data is denoted by the triangles and is defined by

$$
\left(\frac{W_{S}}{W_{R}}\right)_{H}=0.7343212\left[-0.5452493\left(\frac{H_{A}}{H_{S}}\right)^{2}+5.8959291\left(\frac{H_{A}}{H_{S}}\right)-4.2585808\right]^{\left(\frac{1}{3}\right)}-0.6636280
$$

where $\quad \mathrm{W}_{\mathrm{S}}=$ surface wear rate

$\mathrm{W}_{\mathrm{R}}=$ reference wear rate

$\mathrm{H}_{\mathrm{A}}=$ particle (abrasive) hardness (VHN)

$\mathrm{H}_{\mathrm{S}}=$ surface hardness $(\mathrm{VHN})$.

In Sections 3 and 4, hardness values are described for Hanford waste particles, potential simulant components, and DVI valve surfaces. Equation (2.1) can thus be used in the comparison of simulant to Hanford particles to define a surface wear rate relative to a reference wear rate depending on the ratio of the particle hardness to the valve surfaces. With respect to hardness, the maximum wear rate is achieved with $\frac{H_{A}}{H_{S}} \approx 5$ and above, while the minimum wear rate occurs with $\frac{H_{A}}{H_{S}} \approx 0.8$ and below.

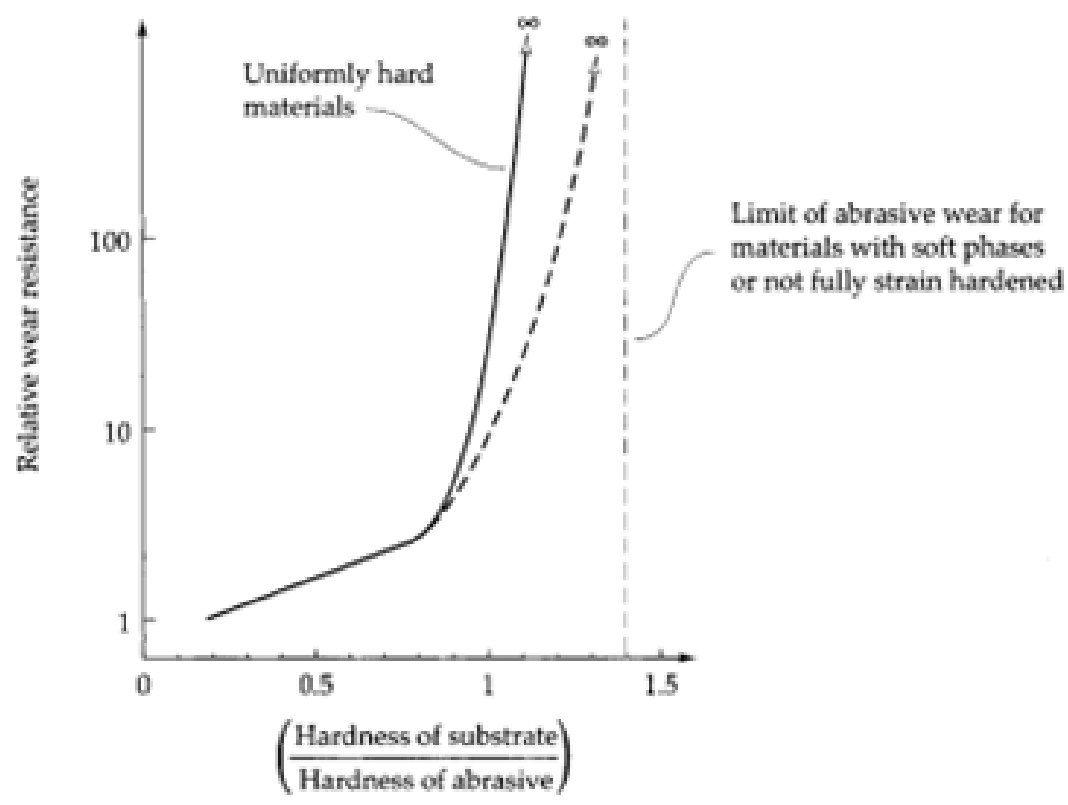

Figure 2.3. Relative Abrasive Wear Resistance as a Function of Hardness Ratio (from Stachowiak and Batchelor 2005) 
Stachowiak and Batchelor (2005) $\triangle$ Fit

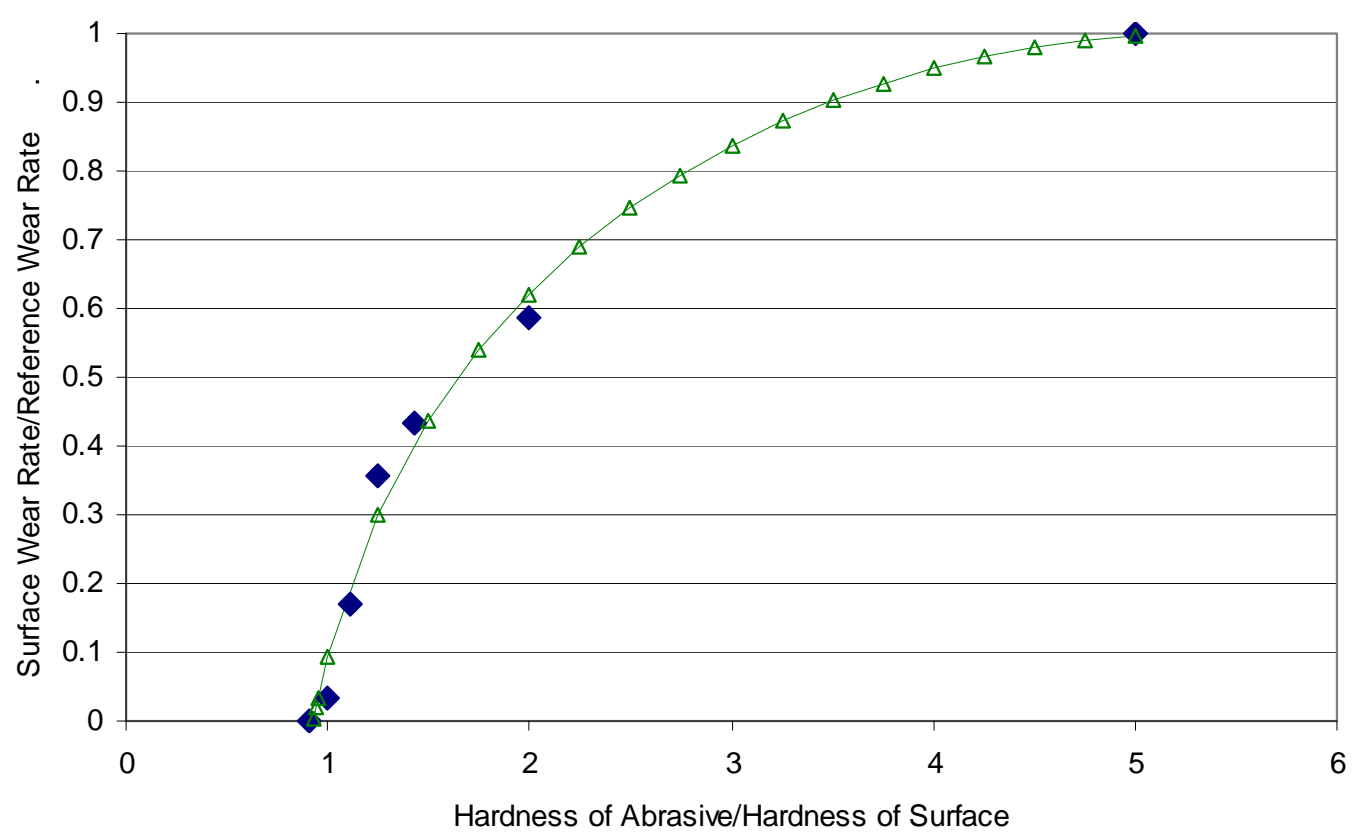

Figure 2.4. Relative Abrasive Wear Rate as a Function of Hardness Ratio

\subsubsection{Particle Size}

De Pellegrin and Stachowiak (2004) describe that, in theory, two-body abrasive wear rates should be independent of particle size with all other parameters equal, but this is not the case in practice. The effect of abrasive particle size on abrasive wear rates is well known (Gåhlin and Jacobson 1999), and Jacobs (2005) cites numerous reports that describe, in general, that abrasive wear rates increase with increasing particle size. However, there is a well-known "size effect" phenomenon wherein above some critical size, the wear rate becomes almost independent of further size increases.

A relation describing the size effect for two-body abrasion is provided in Gåhlin and Jacobson (1999) (Figure 2.5), with a maximum wear rate at the typical critical particle size of $100 \mu \mathrm{m}$. Gåhlin and Jacobson (1999) describe that several theories have been presented to explain the size effect. They concluded that the size effect is likely caused by particle shape (blunt particles exhibit the size effect, ideally sharp particles do not) and wear debris (wear debris can clog the abrasive surface).

With the wear rate of Figure 2.5 normalized using the maximum wear rate as the reference wear rate, a functionality of a surface wear rate with particle size can be defined from Figure 2.5 as

$$
\left(\frac{W_{S}}{W_{R}}\right)_{d}=3.64 E-7 d^{3}-1.418 E-4 d^{2}+0.01818 d+0.2348
$$


where $\mathrm{d}$ is in units of $\mu \mathrm{m}$. The maximum wear rate occurs at a particle size of $100 \mu \mathrm{m}$ and above. The intercept of Equation (2.2) at a zero particle size, $\left(\frac{W_{S}}{W_{R}}\right)_{d}=0.2348$, is non-physical (the Gåhlin and Jacobson (1999) relation stops at $\sim 15 \mu \mathrm{m}$ ) but Equation (2.2) is used for the simulant comparison purposes.

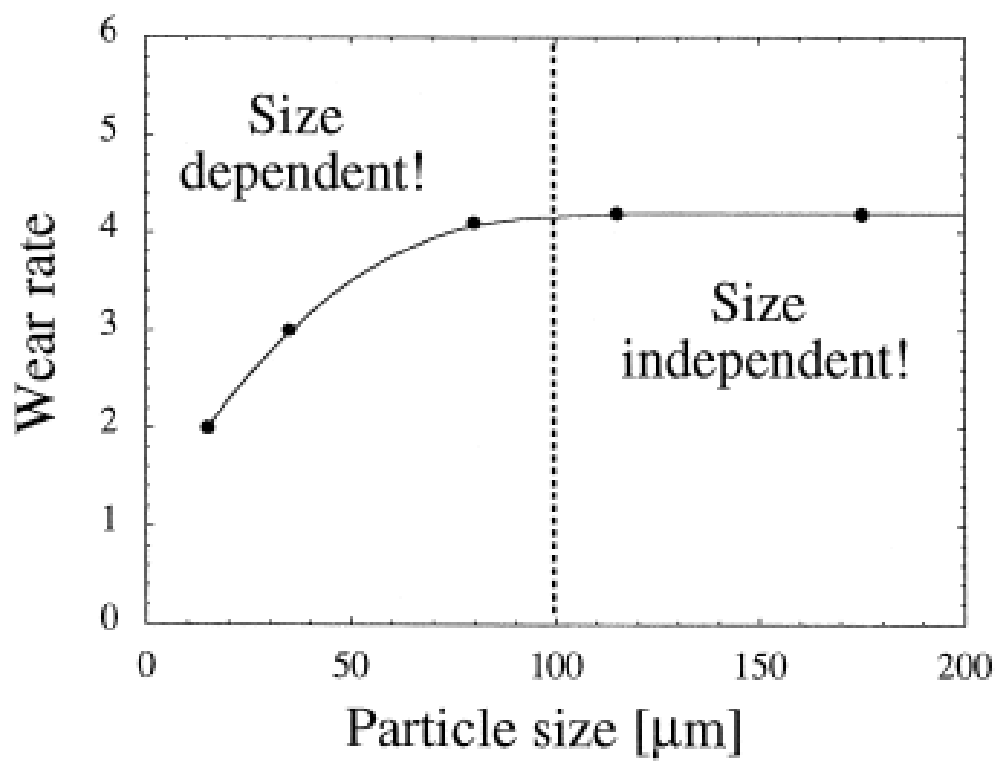

Figure 2.5. Particle-Size Effect in Two-Body Abrasion (from Gåhlin and Jacobson 1999)

\subsubsection{Particle Shape and Surface Characteristics}

The effect of particle shape and surface characteristics on abrasive wear has been extensively investigated in the literature, and shape has a sizable influence on the outcome of abrasive processes (De Pellegrin and Stachowiak 2004). Angular particles will cause more wear than rounded particles (Stachowiak and Batchelor 2005; Jacobs 2005). De Pellegrin and Stachowiak (2004) note that acute tips promote greater cutting efficiency, and Gåhlin and Jacobson (1999) conclude that blunt particles exhibit the size effect, while ideally sharp particles do not. Shipway and Hogg (2007) demonstrated for ceramic wear that with abrasives harder than the surface, wear behavior is dominated by the angularity and particle size distribution of the abrasive. When the abrasives were either softer or not much harder than the surface, the relative hardness dominated the wear mechanisms.

While there is limited information on the general shapes of Hanford waste particles (e.g., Wells et al. 2011), quantification of surface morphologies is even more limited. Thus, although particle shape and surface characteristics clearly influence abrasive wear rates, these effects are not included in the current evaluation. Given that the literature indicates that abrasive wear rates are increased for non-spherical particles, if the waste particles are more non-spherical than the simulant particles, then the comparison is likely to be non-conservative (the waste would have higher abrasion rates than the simulant). The converse is necessarily also true. 
To better define abrasive wear rates, it may be concluded that increased characterization of the particulate with respect to shape and surface is required. While it is reasonably feasible to characterize the simulant components in this respect, the breadth of characterization required for actual Hanford Site waste samples makes this approach at least very difficult if not impossible. ${ }^{1}$ As previously described, however, the interaction between the various factors involved in abrasive wear make it very difficult to isolate the individual effects of the particle properties (Jacobs 2005). A direct measurement of the actual wear rates of materials such as the standard measure of the Miller Number (see previous discussion) is much more useful although the wide variety and sampling issues of Hanford waste would still limit the analysis.

\subsubsection{Valve Surface Abrasion Summary}

Relative abrasive wear rates are described by Equations (2.1) and (2.2) for particle-to-surface hardness ratio and particle size, respectively. Due to the lack of waste particle shape and surface characterization, no relation for abrasive wear to these parameters is described. The waste and simulant particle relative wear rates on the DVI valve surfaces are therefore described by the combination of Equations (2.1) and (2.2) as

$$
\begin{aligned}
& \left(\frac{W_{S}}{W_{R}}\right)_{H}\left(\frac{W_{S}}{W_{R}}\right)_{d}=\left\{0.734\left[-0.545\left(\frac{H_{A}}{H_{S}}\right)^{2}+5.896\left(\frac{H_{A}}{H_{S}}\right)-4.259\right]^{\left(\frac{1}{3}\right)}-0.664\right\} \\
& \left\{3.64 E-7 d^{3}-1.418 E-4 d^{2}+0.018 d+0.235\right\}
\end{aligned}
$$

If, for example, the hardness of the abrasive relative to the valve surface is such that $50 \%$ of the relative (maximum) wear rate is achieved, and the abrasive particle size is likewise such that $50 \%$ of the relative (maximum) wear rate is achieved, the relative wear rate of that particle on that valve surface is determined as 0.25 . As previously described, it is likely that Equation (2.3) does not accurately reflect actual relative abrasive wear rates, but is useful for comparison purposes between the simulant and wastes.

\subsection{Pipeline Critical Transport}

Hanford waste slurry will be transferred through pipelines within tank farms, between tank farms, from tank farms to the WTP, and between process vessels within the WTP. The DVI valve test simulant should, therefore, be representative in performance with respect to pipeline transfer such that similar abrasive particles are presented to the valves during slurry transport in the test loop.

\footnotetext{
${ }^{1}$ For example, see individual solid-phase compounds and likelihood of multi-component agglomerates in Wells et al. (2011).
} 
As for Wells et al. (2012) and Lee et al. (2012), the Oroskar and Turian (1980) model is used to estimate the pipeline critical velocity via

$$
U_{C}=1.85 \sqrt{g d(S-1)} C_{V}^{0.1536}\left(1-C_{V}\right)^{0.3564}\left(\frac{d}{D_{P}}\right)^{-0.378}\left[\frac{D_{P} \rho_{L} \sqrt{g d(S-1)}}{\mu}\right]^{0.09} \chi^{0.30}
$$

where

$$
\begin{aligned}
\mathrm{g} & =\text { gravitational acceleration }\left(\mathrm{m} / \mathrm{s}^{2}\right) \\
\mathrm{S} & =\rho_{\mathrm{S}} / \rho_{\mathrm{L}} \\
\rho_{\mathrm{S}} & =\text { solid particle density }\left(\mathrm{kg} / \mathrm{m}^{3}\right) \\
\rho_{\mathrm{L}} & =\text { liquid density }\left(\mathrm{kg} / \mathrm{m}^{3}\right) \\
\mathrm{C}_{\mathrm{V}} & =\text { solid volume fraction } \\
\mathrm{d}= & \text { particle size }(\mathrm{m}) \\
\mathrm{D}_{\mathrm{P}}= & \text { pipe diameter }(\mathrm{m}) \\
\chi= & \text { fraction of eddies having velocities equal to or greater than the settling velocity. } \\
\mu= & \chi \text { is set to } 0.96(\text { Wells et al. } 2007) .
\end{aligned}
$$

For the comparison evaluation, $\mathrm{C}_{\mathrm{V}}=0.1$ and $\mathrm{D}_{\mathrm{P}}=3$ inches. Water $(1.0 \mathrm{~g} / \mathrm{mL}, 1.0 \mathrm{cP})$ is used as the carrier fluid for Equation (2.4) and all other metric calculations.

\subsection{Pipeline Erosion}

Pipeline wall surface erosion is a process in which a part of the wall material is removed by solids particle impingement on a wall surface as waste slurry is transported. A metric is included to represent this wear in the DVI valve tests.

Gupta et al. (1995) studied the effects of velocity, solids concentration, and particle size on erosion wear around the circumference of a horizontal mild steel pipeline conveying slurries of tailing materials. They derived the following empirical correlation for the wear rate prediction of multi-sized particulate slurries:

$$
E_{\text {pipe }}=0.223 C_{W}^{0.556} d^{0.344} U^{2.148}
$$

where $\quad E_{\text {pipe }}=$ erosion rate of horizontal mild steel straight pipe circumference ( $\mathrm{mm} /$ year)

$\mathrm{U}=$ slurry velocity $(\mathrm{m} / \mathrm{s})$

$\mathrm{d}=$ particle diameter $(\mathrm{m})^{1}$

$\mathrm{C}_{\mathrm{W}}=$ solids concentration by weight. $^{2}$

For the comparison evaluation, $\mathrm{C}_{\mathrm{W}}=0.22$ and $\mathrm{U}=6 \mathrm{ft} / \mathrm{s}(\sim 1.8 \mathrm{~m} / \mathrm{s})$. Note that the effect of particle and surface hardness is not accounted for in Equation (2.5).

\footnotetext{
${ }^{1}$ Units for d are not specified in Gupta et al. (1995). Units of meters are assumed; comparison of results between waste and simulant are of significance, not specific results.

${ }^{2}$ Units for $C_{W}$ are not specified in Gupta et al. (1995); assumed as weight fraction. Comparison of results between waste and simulant are of significance, not specific results.
} 


\subsection{Settling Velocity}

Hanford waste particles are more dense than waste liquids and, therefore, will gravity settle. Cessation of flow in pipeline transport will allow the particles transported in the flow to settle. Thus, the DVI test simulant should have particulate that settles similar to the Hanford waste. At low solids concentrations, individual particles can settle without interacting with other particles (unhindered settling). At higher solids concentrations, interactions between particles can reduce settling rates (hindering settling). For individual particles in the unhindered settling regime, the settling velocity $\left(\mathrm{U}_{\mathrm{T}}\right)$ relation of Camenen (2007) for spherical particles is used as in Wells et al. (2012) and Lee et al. (2012):

$$
U_{T}=\frac{\mu}{\rho_{L} d}\left[\sqrt{15+\sqrt{\frac{A r}{0.3}}}-\sqrt{15}\right]^{2}
$$

where $\mathrm{Ar}$ is the Archimedes number defined by

$$
A r=\frac{\left(\frac{\rho_{S}}{\rho_{L}}-1\right) g d^{3}}{\left(\frac{\mu}{\rho_{L}}\right)^{2}}
$$

$\mathrm{U}_{\mathrm{T}}$ is in $\mathrm{m} / \mathrm{s}$, density terms are in units of $\mathrm{kg} / \mathrm{m}^{3}$, particle size $\mathrm{d}$ is in meters, and viscosity in Pa s.

\subsection{Critical Shear Stress for Particle Erosion}

The critical shear stress for erosion $\left(\tau_{\mathrm{C}}\right)$ is the applied stress required to mobilize particles from the surface of a sediment bed. For the DVI testing, this metric represents the mobilization of particles that may have settled under a condition of no flow in the pipeline. The Paphitis (2001) critical shear stress relation of Wells et al. (2012) and Lee et al. (2012) is used as

$$
\tau_{*}=\frac{0.273}{1+1.2 D_{*}}+0.046\left(1-0.576 e^{-0.02 D_{*}}\right)
$$

where $\mathrm{D}_{*}=\mathrm{Ar}^{1 / 3}$ and

$$
\tau_{*}=\frac{\tau_{C}}{\left(\rho_{S}-\rho_{L}\right) g d}
$$

$\tau_{\mathrm{C}}$ is in units of $\mathrm{Pa}$, density terms are $\mathrm{kg} / \mathrm{m}^{3}$, and particle size $\mathrm{d}$ is in meters. 



\subsection{Valve Surface and Particle Properties}

The DVI valves selected in RPP-PLAN-44556, Rev. 2, to be tested include:

- 2-inch, 2-way Flow-Tek ${ }^{\circledR 1}$ ball valve with ultra-high molecular-weight-polyethylene (UHMWPE) seat

- 2-inch, 3-way Flow-Tek ${ }^{\circledR}$ ball valve with UHMWPE seat

- 3-inch, 2-way Pittsburgh Brass Manufacturing (PBM) ball valve with Tefzel ${ }^{\circledR}$ seat and back-up O-ring

- 3-inch, 3-way PBM ball valve with Tefzel ${ }^{\circledR}$ seat and back up O-ring

- 3-inch, 2-way PBM ball valve with Kynar $^{\circledR}$ seat and back-up O-ring

- 3-inch, 3-way PBM ball valve with $\mathrm{Kynar}^{\circledR}$ seat and back-up O-ring.

The hardness of the valve balls and seats are defined in Section 3.1.

The Hanford Site waste can be characterized with respect to size and density by a particle size and density distribution (PSDD) as developed in Wells et al. (2007). The PSDDs provide a volume-based probability for the solid particles in terms of particle size and density. More specifically, the PSDDs are three-dimensional matrices of the volume probability for each particle size and density pair. PSDDs for characterized Hanford waste are constructed as described in Wells et al. (2011) from measured particle size distributions and undissolved solid composition and density determined from the measured waste chemistry and a combination of modeling and analysis. The hardness values assigned to the undissolved solid compounds are listed in Section 3.2.

Particle properties for the simulant specified in RPP-PLAN-44556, Rev. 2, as defined therein are summarized in Section 3.3.

\subsection{Valves}

The hardness values for the materials of the ball and seat surfaces of the DVI valves listed above are summarized in Table 3.1. Particle abrasive wear is thus considered for a total of five different valve surfaces.

\subsection{Hanford Site Waste Particles}

Wells et al. (2011) provides PSDDs for individual Hanford Site tanks that have particle size distribution data available, the primary waste types represented by that particle size distribution data, and sludge and saltcake waste type composites created from the available data. The general waste types, sludge and saltcake, are classified as such based on the relative concentrations of soluble and insoluble undissolved solids. As specified in Weber (2009), a tank's content is classified as sludge if at least $75 \mathrm{vol} \%$ is sludge solids (insoluble undissolved solids), and classified as saltcake if it is at least 75 vol\% saltcake/salt slurry solids (soluble undissolved solids). Only those tanks and waste types that are primarily sludge are considered for the DVI valve simulant evaluation because retrieval activities can

\footnotetext{
${ }^{1}$ Flow-Tek is a registered trademark of Bray International, Inc., Houston, Texas.
} 
dissolve the soluble waste. This approach is conservative with respect to particle hardness given that sludge particles (i.e., those particles that are insoluble relative to water; non-salt) are typically harder than salt particles as presented below.

Uncertainties in the particulate characterization of the PSDDs include:

1. Particle density. The particle density of the PSDDs is determined by the undissolved solid composition and assumptions about that composition and the density of the particulate as it exists as primary particles, hard agglomerates, and soft agglomerates or flocs.

2. Particle size. In addition to the uncertainty of the particle size distribution measurement techniques themselves, applying a measurement technique under different instrumentation configurations can yield different results.

Table 3.1. Hardness of DVI Valve Surfaces

\begin{tabular}{|c|c|c|c|}
\hline $\begin{array}{c}\text { Valve } \\
\text { Manufacturer }\end{array}$ & $\begin{array}{c}\text { Ball Material(s) } \\
{[\text { Hardness }(\mathrm{VHN})]}\end{array}$ & $\begin{array}{c}\text { Seat Material(s) } \\
{[\text { Hardness }(\mathrm{VHN})]}\end{array}$ & References \\
\hline Flow-Tek $^{\circledR}$ & $\begin{array}{c}316 \text { SS (stainless steel) ASTM } \\
\text { A351 CF8M } \\
{[174]}\end{array}$ & $\begin{array}{c}\text { UHMWPE } \\
{[467]}\end{array}$ & Flow-Tek ${ }^{\circledR}$ Valve Brochure ${ }^{(a)}$ \\
\hline \multirow[b]{2}{*}{ PBM } & $\begin{array}{c}316 \text { SS ASTM A351 CF8M } \\
{[174]}\end{array}$ & $\begin{array}{c}\text { Tefzel }{ }^{\circledR} \text { HT-2181 } \\
{[511]}\end{array}$ & $\begin{array}{l}\text { DuPont }^{\mathrm{TM}} \text { Tefzel } \\
\text { Product Information }\end{array}$ \\
\hline & $\begin{array}{c}0.0002 \text { to } 0.001 \text { in. nickel coating } \\
\text { [989] }\end{array}$ & $\begin{array}{c}\text { Kynar }^{\circledR} 700 \text { Series } \\
{[627]}\end{array}$ & $\begin{array}{c}\text { Kynar }^{(\mathbb{P}} \text { \& Kynar Flex } \\
\text { PVDF Performance and } \\
\text { Characteristics Data, Arkema } \\
\text { Cha }\end{array}$ \\
\hline
\end{tabular}

(a) Personal communication from JK Engeman, WRPS, to BE Wells, PNNL, August 6, 2012.

(b) Kynar Flex is a registered trademark of Arkema Inc., Philadelphia, Pennsylvania.

Further, only a limited fraction of the waste has been characterized. Following Lee et al. (2012), the No-Flow Unsonicated sludge waste PSDDs of Wells et al. (2011) are used to represent the waste for the DVI simulant comparison. The No-Flow Unsonicated PSDD type data show the largest particulate as well as the largest tank-to-tank variability. Approximately 18 vol\% of the Hanford sludge undissolved solids is characterized by the No-Flow Unsonicated PSDDs, and it is possible that the variation in the limited characterization of the waste under-represents the variation of the waste inventory, Wells et al. (2012).

The specific No-Flow Unsonicated PSDDs are provided in electronic form with Wells et al. (2011), and, given their large size, are not reproduced here. Wells et al. (2011) did not include hardness information for the solid-phase compounds, so a list of the sludge waste compounds and hardness values selected to represent those compounds as determined from the literature are provided in Table 3.2 and Table 3.3 for non-salt and salt sludge waste tank compounds, respectively. The crystal densities from Wells et al. (2011) of the solid-phase compounds are also listed. The non-salt particle hardness range is 3 to $8 \mathrm{Mohs}$, and the salt particle hardness range is 1.3 to $2.7 \mathrm{Mohs}$. As with the density values, these hardness values represent the solid-phase compound crystal or primary particles and do not take into account agglomeration. 
Table 3.2. Hanford Sludge Non-Salt Particle Hardness (solid-phase compounds from Wells et al. 2011)

\begin{tabular}{|c|c|c|c|}
\hline Non-Salt Solid-Phase Compounds & $\begin{array}{c}\text { Crystal Density } \\
(\mathrm{g} / \mathrm{mL})\end{array}$ & Mohs Hardness & $\mathrm{VHN}^{(\mathrm{a})}$ \\
\hline $\mathrm{Ag}$ & 10.5 & 3 & 157 \\
\hline $\mathrm{Ag}_{2} \mathrm{O}$ & 7.143 & 3 & 157 \\
\hline $\mathrm{Bi}_{2} \mathrm{O}_{3}$ & 8.9 & 4.5 & 418 \\
\hline $\mathrm{BiFeO}_{3}$ & 7.9 & 4.5 & 418 \\
\hline $\mathrm{Ca}_{5} \mathrm{OH}(\mathrm{PO} 4)_{3}$ & 3.14 & 5 & 535 \\
\hline $\mathrm{CaCO}_{3}$ & 2.71 & 3 & 157 \\
\hline $\mathrm{CaF}_{2}$ & 3.18 & 4 & 315 \\
\hline $\mathrm{CrOOH}$ & 4.11 & 4.5 & 418 \\
\hline $\mathrm{FePO}_{4} \cdot 2 \mathrm{H}_{2} \mathrm{O}$ & 3.15 & 4 & 315 \\
\hline $\mathrm{FeOOH}$ & 4.26 & 5.5 & 669 \\
\hline Gibbsite & 2.42 & 3 & 157 \\
\hline Boehmite & 3.01 & 4 & 315 \\
\hline $\mathrm{HgO}$ & 7.143 & 3 & 157 \\
\hline $\mathrm{KAlSiO}_{4}$ & 2.61 & 6 & 817 \\
\hline $\mathrm{La}(\mathrm{OH})_{3}$ & 2.3 & 4.9 & 511 \\
\hline $\mathrm{LaPO}_{4} \cdot 2 \mathrm{H}_{2} \mathrm{O}$ & 6.51 & 4.9 & 511 \\
\hline $\mathrm{Mn}_{3}\left(\mathrm{PO}_{4}\right)_{2}$ & 3.102 & 3.5 & 229 \\
\hline $\mathrm{MnO}_{2}$ & 5.026 & 6.5 & 982 \\
\hline $\mathrm{Na}_{2}\left(\mathrm{UO}_{2}\right)_{2}\left(\mathrm{PO}_{4}\right)_{2} \cdot 2 \mathrm{H}_{2} \mathrm{O}$ & 3.5 & 5 & 535 \\
\hline $\mathrm{Na}_{2} \mathrm{U}_{2} \mathrm{O}_{7}$ & 5.617 & 5 & 535 \\
\hline $\mathrm{NaAlCO}_{3}(\mathrm{OH})_{2}$ & 2.42 & 3 & 157 \\
\hline $\mathrm{NaAlSiO}_{4}$ & 2.365 & 6 & 817 \\
\hline $\mathrm{Ni}(\mathrm{OH})_{2}$ & 4.15 & 3.95 & 306 \\
\hline $\mathrm{Ni}_{3}\left(\mathrm{PO}_{4}\right)_{2}$ & 3.93 & & 55 \\
\hline $\mathrm{NiC}_{2} \mathrm{O}_{4} \cdot 2 \mathrm{H}_{2} \mathrm{O}$ & 4.26 & 8 & 1567 \\
\hline $\mathrm{Pb}(\mathrm{OH})_{2}$ & 7.1 & 3.5 & 229 \\
\hline $\mathrm{Pb}_{3}(\mathrm{PO} 4)_{2}$ & 7.1 & 3.5 & 229 \\
\hline $\mathrm{PbCO}_{3}$ & 6.6 & 3 & 157 \\
\hline $\mathrm{Pu}(\mathrm{OH})_{4}$ (co-precip. on Fe phase) & 4.26 & 8 & 1567 \\
\hline $\mathrm{PuO}_{2}$ & 11.43 & 8 & 1567 \\
\hline $\mathrm{SiO}_{2}$ & 2.6 & 7 & 1161 \\
\hline $\mathrm{Sr}_{3}\left(\mathrm{PO}_{4}\right)_{2}$ & 3.5 & 3.5 & 229 \\
\hline $\mathrm{SrCO}_{3}$ & 3.5 & 3.5 & 229 \\
\hline $\mathrm{ZrO}_{2}$ & 5.68 & 6.5 & 982 \\
\hline
\end{tabular}

(a) Different references provide similar but not equivalent conversions from Mohs to Vickers hardness. Data provided at http://www.cidraprecisionservices.com/mohs-conversion.html, in general agreement with the ranges provided in Stachowiak and Batchelor (2005), was used for this analysis. 
Table 3.3. Hanford Sludge Salt Particle Hardness (solid-phase compounds from Wells et al. 2011)

\begin{tabular}{lccc}
\hline \multicolumn{1}{c}{$\begin{array}{c}\text { Salt Solid-Phase } \\
\text { Compounds }\end{array}$} & $\begin{array}{c}\text { Crystal Density } \\
(\mathrm{g} / \mathrm{mL})\end{array}$ & Mohs Hardness & VHN $^{(\mathrm{a})}$ \\
\hline $\mathrm{Na}_{2} \mathrm{C}_{2} \mathrm{O}_{4}$ & 2.34 & 3 & 157 \\
$\mathrm{Na}_{2} \mathrm{CO}_{3} \cdot \mathrm{H}_{2} \mathrm{O}$ & 2.25 & 1.3 & 31 \\
$\mathrm{Na}_{2} \mathrm{SO}_{4}$ & 2.68 & 2.7 & 122 \\
$\mathrm{Na}_{2} \mathrm{SO}_{4} \cdot 10 \mathrm{H}_{2} \mathrm{O}$ & 1.464 & 1.8 & 49 \\
$\mathrm{Na}_{3} \mathrm{FSO}_{4}$ & 2.65 & 2.5 & 102 \\
$\mathrm{Na}_{3} \mathrm{NO}_{3} \mathrm{SO}_{4} \cdot \mathrm{H}_{2} \mathrm{O}$ & 2.3 & 2 & 61 \\
$\mathrm{Na}_{3} \mathrm{PO}_{4} \cdot 0.25 \mathrm{NaOH} \cdot 12 \mathrm{H}_{2} \mathrm{O}$ & 1.62 & 2.5 & 102 \\
$\mathrm{Na}_{4} \mathrm{P}_{2} \mathrm{O}_{7} \cdot 10 \mathrm{H}_{2} \mathrm{O}$ & 1.83 & 2.5 & 102 \\
$\mathrm{Na}_{6}\left(\mathrm{SO}_{4}\right)_{2} \mathrm{CO}_{3}$ & 2.64 & 2.7 & 122 \\
$\mathrm{NaF}$ & 2.78 & 2.3 & 84 \\
$\mathrm{Na}_{7} \mathrm{~F}_{\left(\mathrm{PO}_{4}\right)_{2} \cdot 19 \mathrm{H}} \mathrm{O}$ & 1.75 & 2.5 & 102 \\
$\mathrm{NaHCO}_{3}$ & 2.159 & 2.5 & 102 \\
$\mathrm{NaNO}_{2}$ & 2.168 & 2.5 & 102 \\
$\mathrm{NaNO}_{3}$ & 2.26 & 2 & 61 \\
\hline
\end{tabular}

(a) Different references provide similar but not equivalent conversions from Mohs to Vickers hardness. Data provided at http://www.cidraprecisionservices.com/mohsconversion.html, in general agreement with the ranges provided in Stachowiak and Batchelor (2005), was used for this analysis.

\subsection{RPP-PLAN-44556, Rev. 2, Simulant Particles}

The DVI valve test simulant specified in RPP-PLAN-44556, Rev. 2, is summarized in Table 3.4. This simulant was originally developed to support resolution of issue M2, Mixing Vessel Erosion, raised by the External Flowsheet Review Team with respect to the WTP, CCN 132846 and 24590-WTP-PLENG-06-0012 Rev. 2. 
Table 3.4. RPP-PLAN-44556, Rev. 2 DVI Valve Test Simulant

\begin{tabular}{|c|c|c|c|c|c|}
\hline Solids & Mass $(\%)$ & Volume (\%) & $\begin{array}{l}\text { Crystal } \\
\text { Density } \\
(\mathrm{g} / \mathrm{mL})\end{array}$ & $\begin{array}{c}\text { Mohs } \\
\text { Hardness }\end{array}$ & $\begin{array}{c}\text { Nominal } \\
\operatorname{Size}^{(\mathrm{a})}(\mu \mathrm{m}) \\
\end{array}$ \\
\hline $\begin{array}{l}\mathrm{Al}(\mathrm{OH})_{3} \text { - Medium as Almatis } \\
\mathrm{C}-333\end{array}$ & 32.03 & 36.25 & 2.42 & 3 & 7 \\
\hline $\begin{array}{l}\mathrm{Al}(\mathrm{OH})_{3} \text { - Coarse Gibbsite as } \\
\text { Almatis C-31C }\end{array}$ & 13.1 & 14.82 & 2.42 & 3 & 85 \\
\hline Zeolite- ZEO Z-Ultra & 14.3 & 18.21 & 2.15 & 3.75 & 4.5 \\
\hline $\begin{array}{l}\text { AlOOH - Boehmite as BASF } \\
\mathrm{Hi}-10\end{array}$ & 11.5 & 10.46 & 3.01 & 3.75 & 55 \\
\hline $\begin{array}{l}\mathrm{Al}(\mathrm{OH}) 3 \text { - Medium as Almatis } \\
\mathrm{C}-333\end{array}$ & 8.3 & 9.39 & 2.42 & 3 & 7 \\
\hline Prince $\mathrm{Fe}_{2} \mathrm{O}_{3}$ (No. 08-2568) & 7.8 & 4.08 & 5.24 & 5.5 & 0.6 \\
\hline Alpha Aesar $\mathrm{Ca}_{5} \mathrm{OH}\left(\mathrm{PO}_{4}\right)_{3}$ & 2.3 & 2.01 & 3.14 & 5 & 30 \\
\hline Cerac $\mathrm{Bi}_{2} \mathrm{O}_{3}$ & 3.2 & 0.98 & 8.9 & 4.5 & 15 \\
\hline Cerac $\mathrm{ZrO}_{2}$ & 2.2 & 1.06 & 5.68 & 6.5 & 10 \\
\hline Cerac $\mathrm{Bi}_{2} \mathrm{O}_{3}$ & 2.6 & 0.8 & 8.9 & 4.5 & 15 \\
\hline $\begin{array}{l}\text { Silica powder - rounded - } \\
\text { OK-110 }\end{array}$ & 0.6 & 0.62 & 2.65 & 7 & 110.5 \\
\hline Aldrich $\mathrm{Ni}(\mathrm{OH})_{2}$ & 0.8 & 0.53 & 4.1 & 3.5 & 20 \\
\hline Aldrich $\mathrm{MnO}_{2}$ & 1 & 0.54 & 5.03 & 6.25 & 5 \\
\hline Aldrich $\mathrm{CaF}_{2}$ & 0.27 & 0.23 & 3.18 & 4 & 12 \\
\hline
\end{tabular}

(a) "Nominal size" as denoted by RPP-PLAN-44556, Rev. 2 



\subsection{Comparison of Hanford Waste and Simulants}

Comparison of the DVI valve test simulant and Hanford Site waste particulate defined in Section 3 is made on the following metrics described in Section 2:

1-5. Valve surface relative abrasive wear rate, $\left(\frac{W_{S}}{W_{R}}\right)_{H}\left(\frac{W_{S}}{W_{R}}\right)_{d}$, Equation (2.3), for stainless steel, nickel plating, Tefzel ${ }^{\circledR}, \mathrm{Kynar}^{\circledR}$, and UHMWPE.

6. Pipeline critical transport velocity, $\mathrm{U}_{\mathrm{C}}$, Equation (2.4)

7. Pipeline erosion rate, $\mathrm{E}_{\text {pipe, }}$ Equation (2.5)

8. Archimedes number, Ar, Equation (2.7)

9. Settling velocity, $\mathrm{U}_{\mathrm{T}}$, Equation (2.6)

10. Critical shear stress for erosion of non-cohesive particles, $\tau_{\mathrm{c}}$, from Equations (2.8) and (2.9)

The primary metrics describe valve surface abrasion due to particle interaction, and the secondary metrics for pipeline transfer and erosion represent the slurry as it is flowing through the piping, particle settling under conditions of no flow, and particle suspension for conditions of re-establishing flow.

The waste and simulant particles as described by their PSDDs and hardness are compared via these models with all inputs held constant at the values specified in Section 2 and water $(1.0 \mathrm{~g} / \mathrm{mL}, 1.0 \mathrm{cP})$ is used as the fluid in all cases. Other parameters that may influence the comparison not encompassed in the model forms (e.g., particle shape, see Section 2) are not addressed. As discussed in Section 2, it is the comparison of the metrics for the waste and simulant particulate that is of significance, not the specific model results.

The RPP-PLAN-44556, Rev. 2, DVI valve test simulant as defined by Table 3.4 is compared to the waste in Section 4.1. As a result of this comparison, an alternate target waste design criteria was defined and an adjusted simulant was designed as described in Section 4.2.

\subsection{RPP-PLAN-44556, Rev. 2, Simulant Comparison}

Comparison plots for the 10 metrics are provided in Figure 4.1 through Figure 4.10. In each figure, the abscissa is the metric and the ordinate is the cumulative undissolved solids (UDS) volume $\%$ summed in increasing order of the metric. Thus, for example, the settling velocity at $60 \%$ indicates that $60 \%$ of the particulate by volume has a lower calculated settling velocity, and $40 \%$ by volume has a higher settling velocity. For each metric, the results for the RPP-PLAN-44556, Rev. 2, simulant are labeled as "M2 Simulant" and indicated by the red line and square symbols. The black line and symbol on each plot is the composite waste result labeled Sludge, No-Flow Unsonicated and represents the volume-weighted combination of all the tank waste represented in the plot. 


\begin{tabular}{|c|c|c|}
\hline$C-107$ & BX-107 & T-104 \\
\hline B-201 & - B-111 & $-\mathrm{T}-111$ \\
\hline AY -102 & $\longrightarrow$ C-104 & C-103 \\
\hline AZ-101 & $A Z-102$ & $-\mathrm{U}-110$ \\
\hline SY-102 & $\rightarrow$ Sludge, No-Flow Unsonicated & $\longrightarrow$ M2 Simulant \\
\hline
\end{tabular}

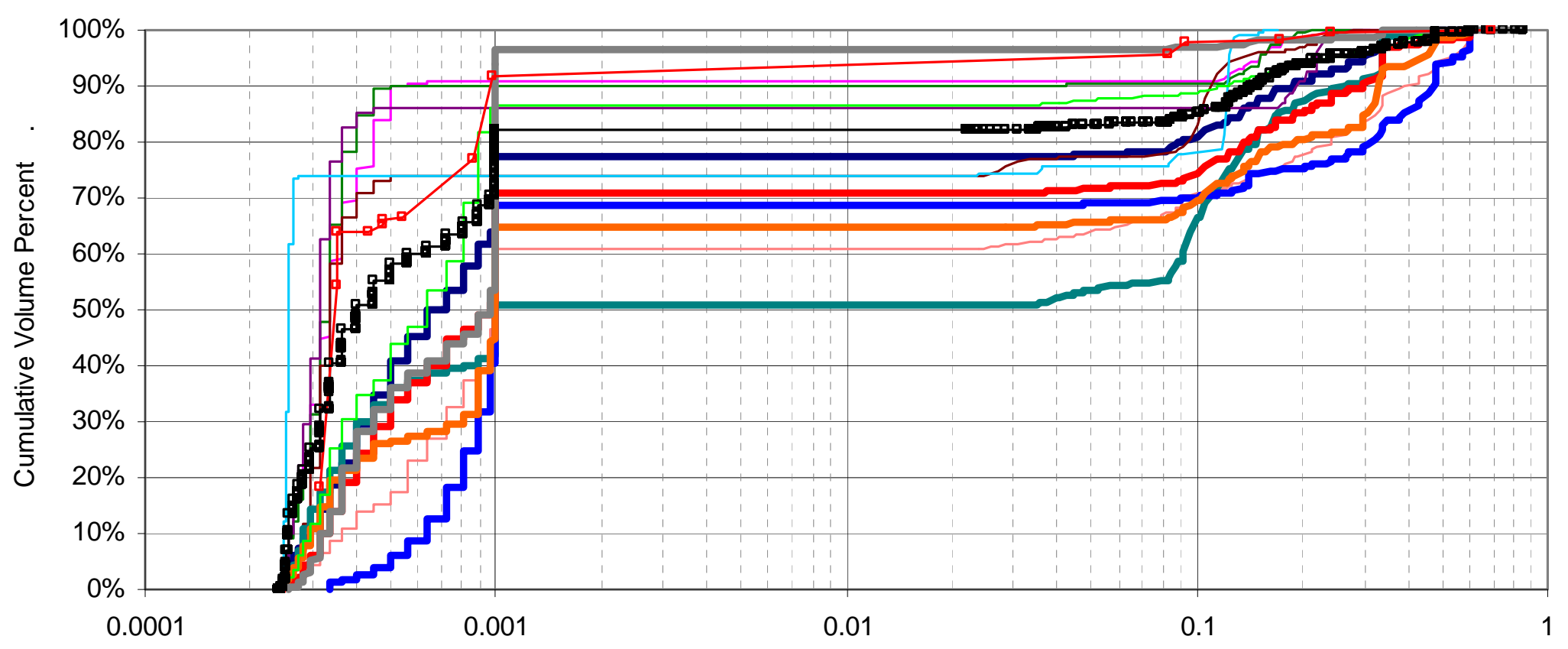

Tefzel (Wear Rate/Reference Wear Rate)Hardness X (Wear Rate/Reference Wear Rate)Diameter

Figure 4.1. Tefzel ${ }^{\circledR}$ Valve Seat Reference Wear Rate Comparison. RPP-PLAN-44556, Rev. 2, "M2 Simulant," red line and square symbols; composite waste, black line and symbol. 


\begin{tabular}{|lll|}
\hline C-107 & - BX-107 & T-104 \\
B-201 & - B-111 & -111 \\
AY-102 & C-104 & C-103 \\
AZ-101 & $\rightarrow$ AZ-102 & -110 \\
SY-102 & $\longrightarrow$ Sludge, No-Flow Unsonicated & - M2 Simulant \\
\hline
\end{tabular}

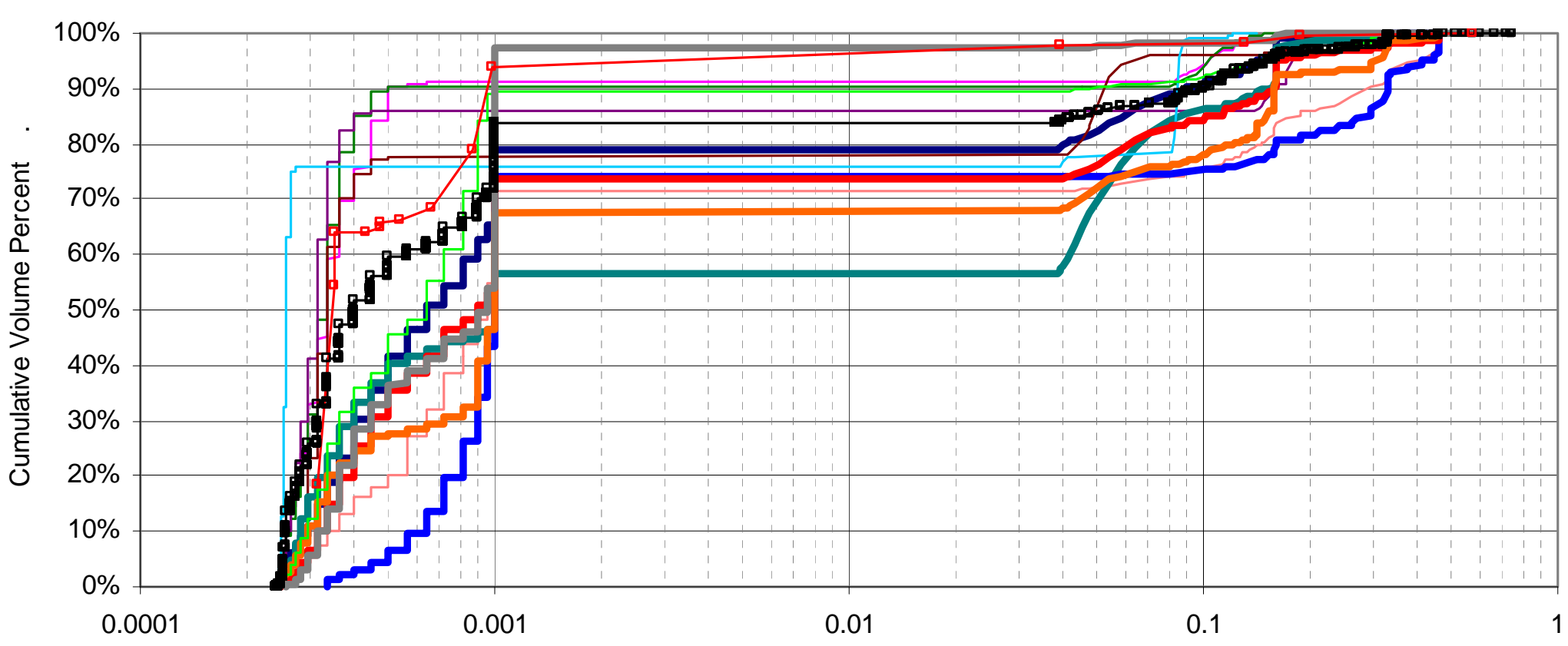

Kynar (Wear Rate/Reference Wear Rate)Hardness X (Wear Rate/Reference Wear Rate)Diameter

Figure 4.2. Kynar $^{\circledR}$ Valve Seat Reference Wear Rate Comparison. RPP-PLAN-44556, Rev. 2, "M2 Simulant," red line and square symbols; composite waste, black line and symbol. 


\begin{tabular}{|lll|}
\hline C-107 & $-\mathrm{BX}-107$ & $-\mathrm{T}-104$ \\
$\mathrm{~B}-201$ & $-\mathrm{B}-111$ & $-\mathrm{T}-111$ \\
$\mathrm{AY}-102$ & $\mathrm{C}-103$ \\
$\mathrm{AZ}-101$ & $-\mathrm{C}-103-102$ \\
SY-102 & $\rightarrow$ Sludge, No-Flow Unsonicated & $-\mathrm{M} 2$ Simulant \\
\hline
\end{tabular}

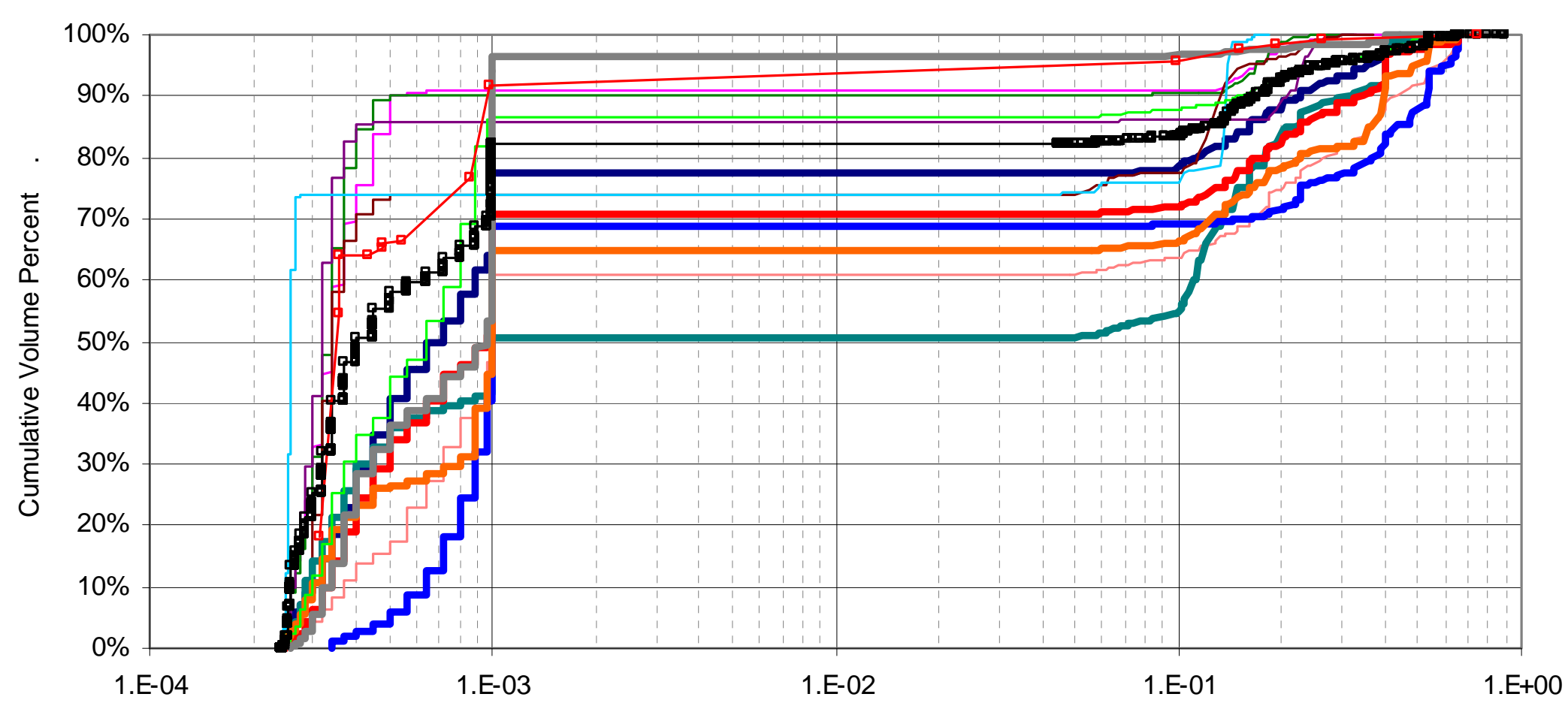

UHMWPE (Wear Rate/Reference Wear Rate)Hardness X (Wear Rate/Reference Wear Rate)Diameter

Figure 4.3. UHMWPE Valve Seat Reference Wear Rate Comparison. RPP-PLAN-44556, Rev. 2, "M2 Simulant," red line and square symbols; composite waste, black line and symbol. 

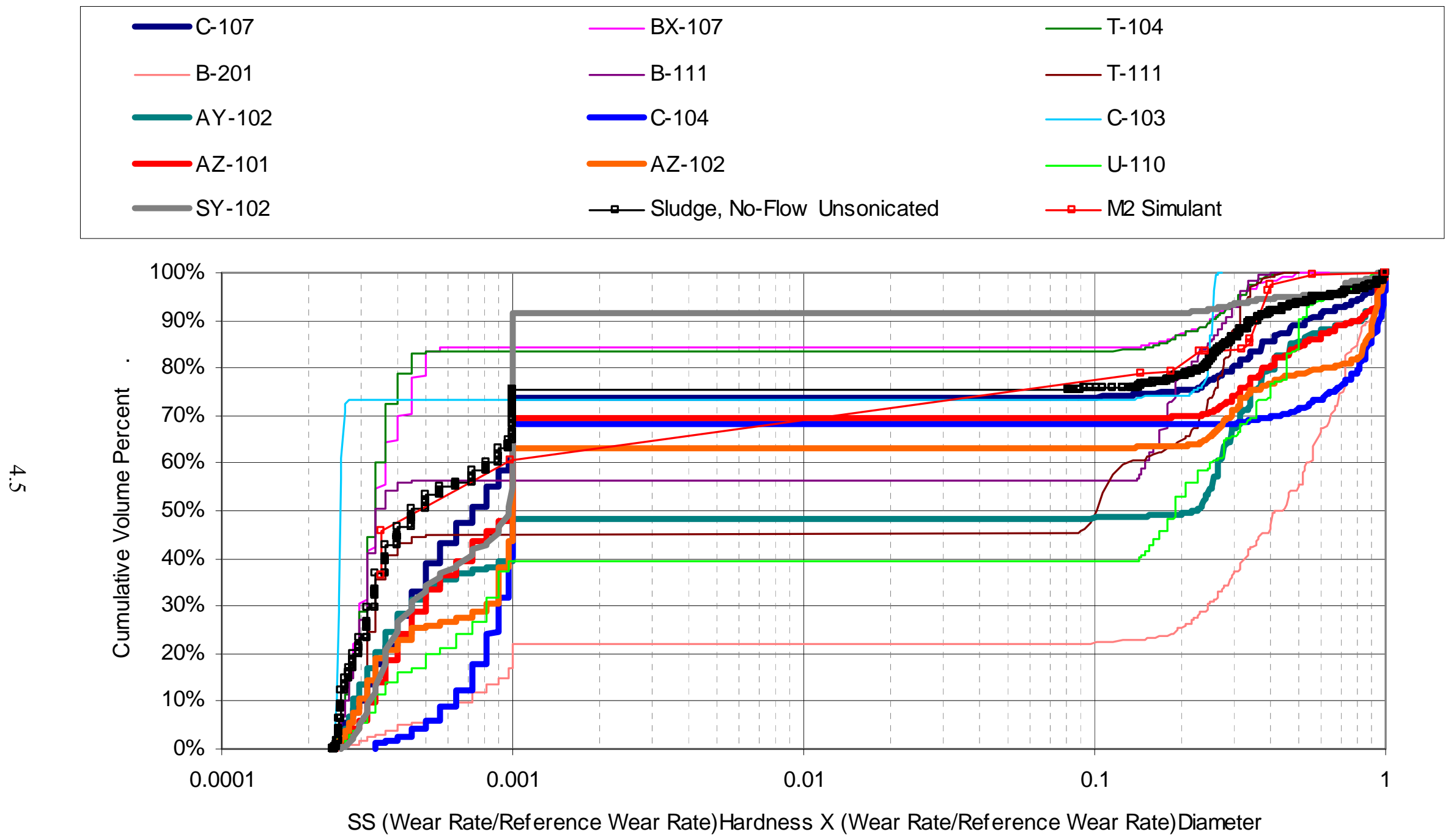

Figure 4.4. Stainless Steel Valve Ball Reference Wear Rate Comparison. RPP-PLAN-44556, Rev. 2, "M2 Simulant," red line and square symbols; composite waste, black line and symbol. 


\begin{tabular}{|lll|}
\hline C-107 & BX-107 & - T-104 \\
B-201 & B-111 & -111 \\
AY-102 & C-104 & -103 \\
AZ-101 & AZ-102 & U-110 \\
SY-102 & $\longrightarrow$ Sludge, No-Flow Unsonicated & $\longrightarrow$ M2 Simulant \\
\hline
\end{tabular}

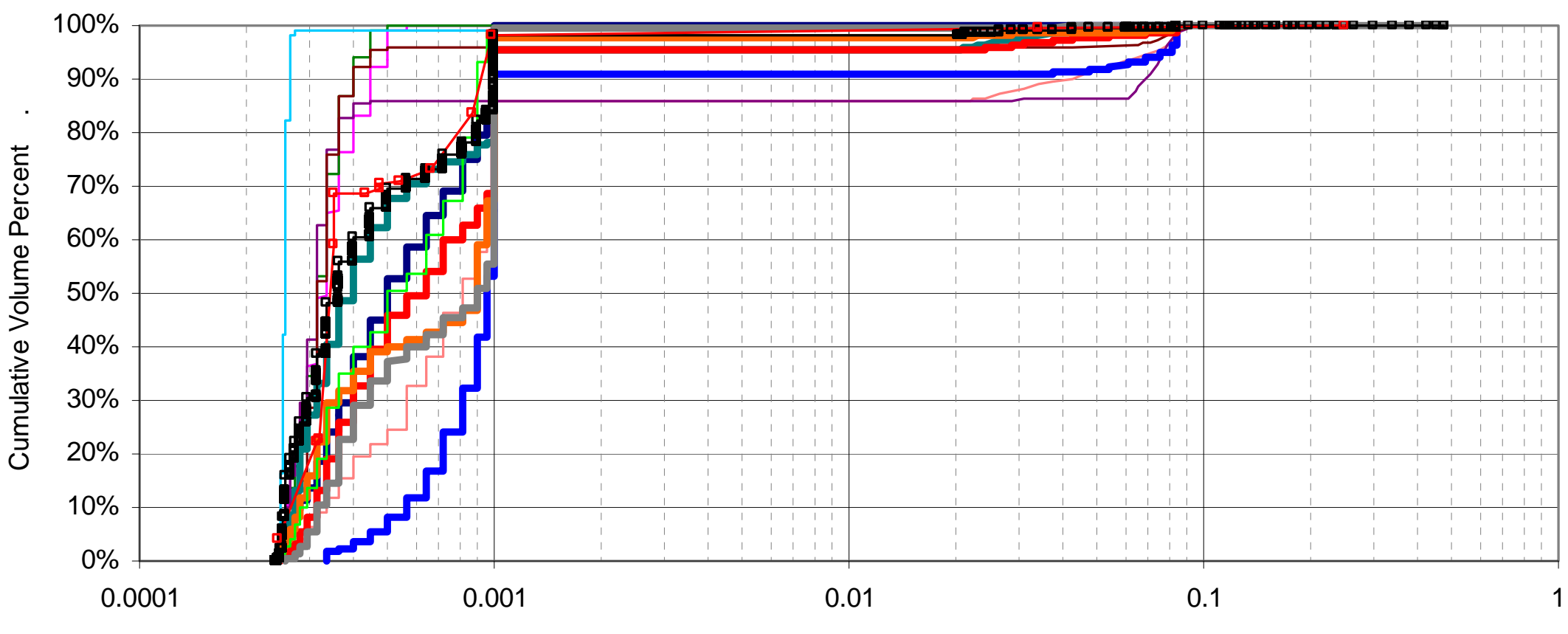

Nickel Plating (Wear Rate/Reference Wear Rate)Hardness X (Wear Rate/Reference Wear Rate)Diameter

Figure 4.5. Nickel Plating Valve Ball Reference Wear Rate Comparison. RPP-PLAN-44556, Rev. 2, "M2 Simulant," red line and square symbols; composite waste, black line and symbol. 


\begin{tabular}{|c|c|c|}
\hline C-107 & BX-107 & T-104 \\
\hline B-201 & - B-111 & — T-111 \\
\hline$A Y-102$ & $\longrightarrow$ C-104 & — C-103 \\
\hline AZ-101 & $\longrightarrow A Z-102$ & $-\mathrm{U}-110$ \\
\hline SY-102 & $\rightarrow$ Sludge, No-Flow Unsonicated & $\rightarrow$ M2 Simulant \\
\hline
\end{tabular}

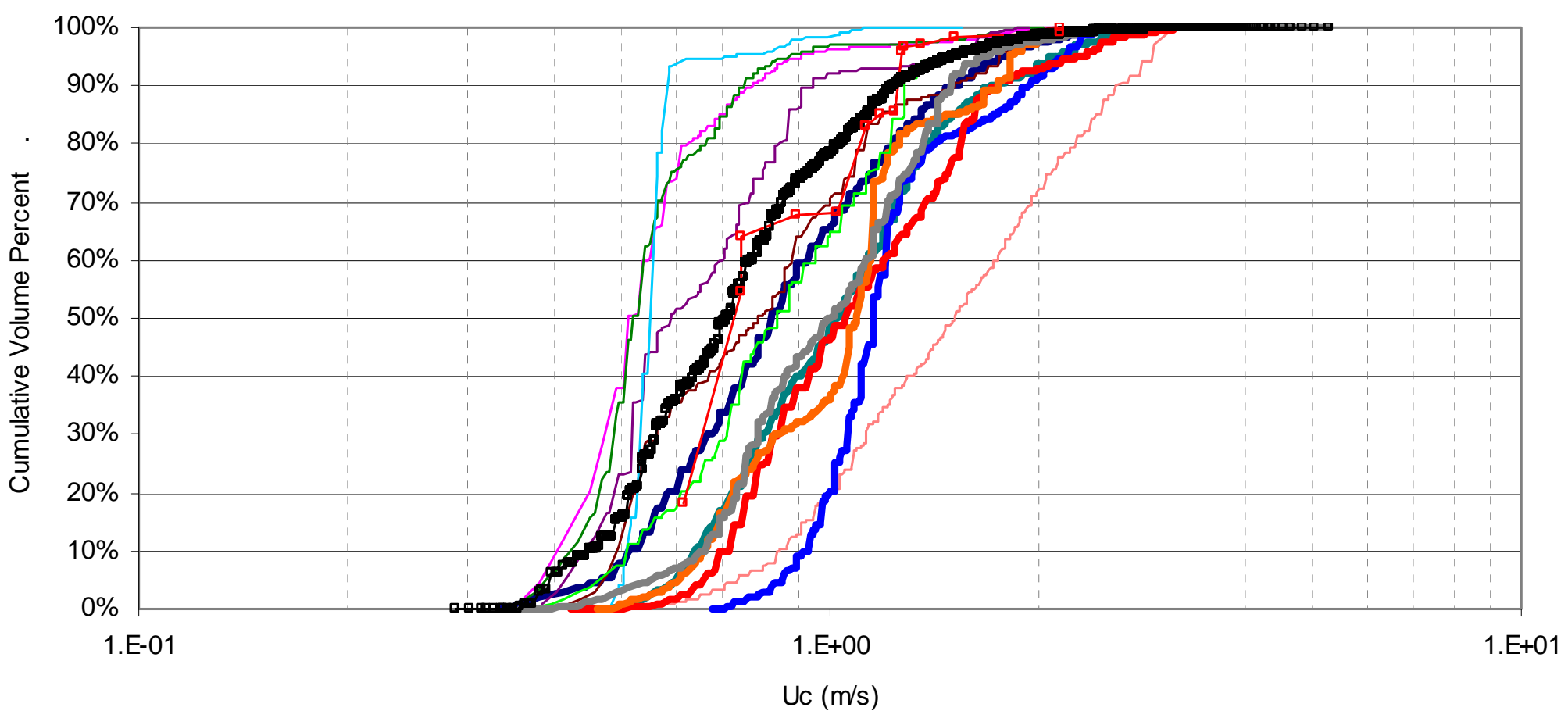

Figure 4.6. Pipeline Critical Transport Velocity Comparison. RPP-PLAN-44556, Rev. 2, "M2 Simulant," red line and square symbols; composite waste, black line and symbol. 


\begin{tabular}{|lll|}
\hline C-107 & - BX-107 & - T-104 \\
B-201 & - B-111 & - T-111 \\
AY-102 & C-104 103 \\
AZ-101 & AZ-102 & - U-110 \\
SY-102 & $\rightarrow$ Sludge, No-Flow Unsonicated & $-\mathrm{M} 2$ Simulant \\
\hline
\end{tabular}

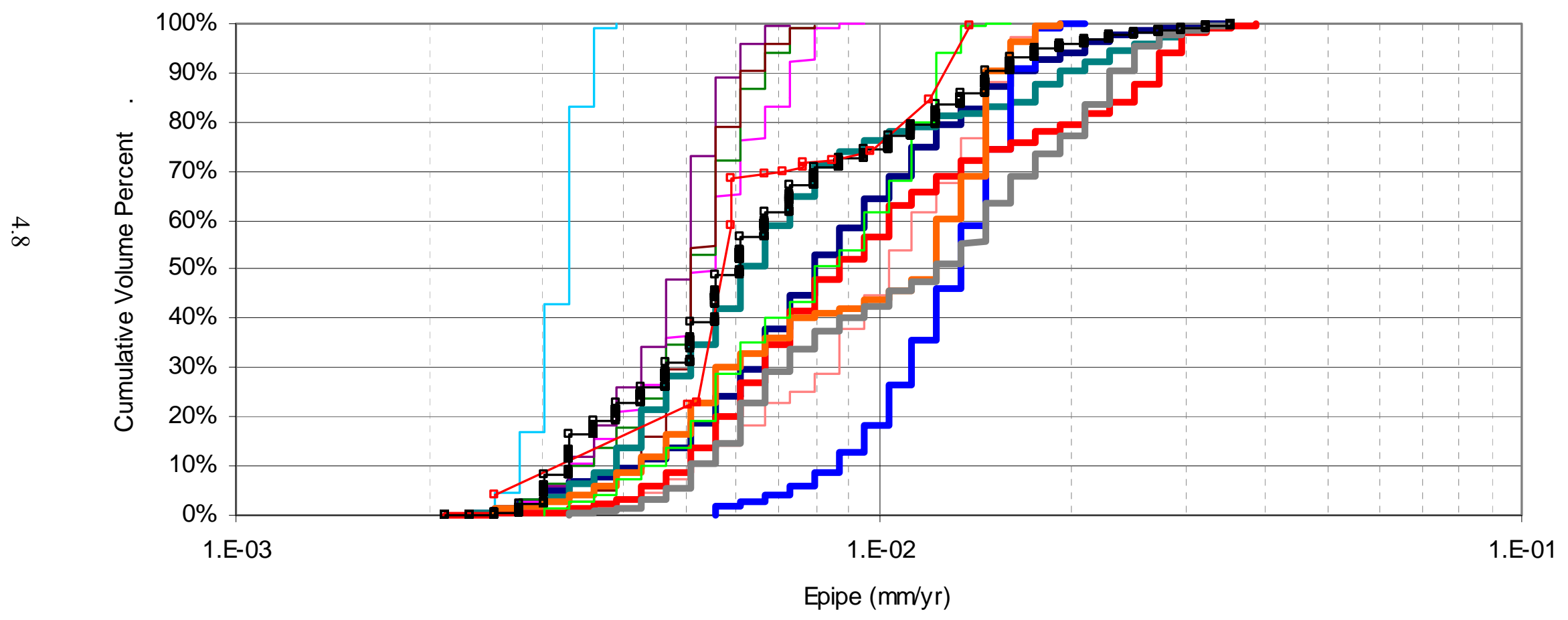

Figure 4.7. Pipeline Erosion Rate Comparison. RPP-PLAN-44556, Rev. 2, "M2 Simulant," red line and square symbols; composite waste, black line and symbol. 


\begin{tabular}{|c|c|c|}
\hline $\mathrm{C}-107$ & BX-107 & $-\mathrm{T}-104$ \\
\hline B-201 & - B-111 & $-\mathrm{T}-111$ \\
\hline$A Y-102$ & $\longrightarrow$ C-104 & $-\mathrm{C}-103$ \\
\hline AZ-101 & $\longrightarrow \mathrm{AZ}-102$ & $-\mathrm{U}-110$ \\
\hline$\longrightarrow$ SY-102 & $\rightarrow$ Sludge, No-Flow Unsonicated & $\longrightarrow-\mathrm{M} 2$ Simulant \\
\hline
\end{tabular}

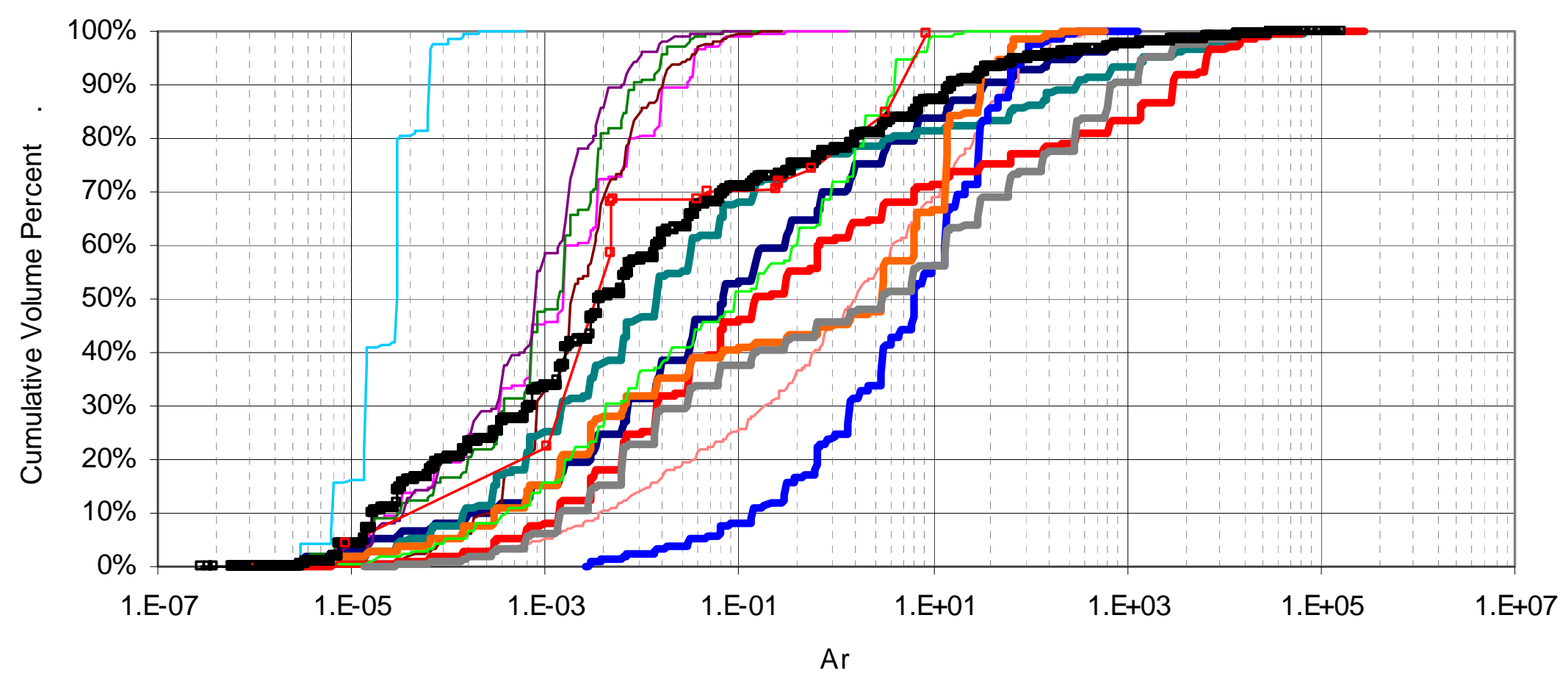

Figure 4.8. Archimedes Number Comparison. RPP-PLAN-44556, Rev. 2, "M2 Simulant," red line and square symbols; composite waste, black line and symbol. 


\begin{tabular}{|c|c|c|}
\hline$\longrightarrow \mathrm{C}-107$ & BX-107 & T-104 \\
\hline B-201 & - B-111 & - T-111 \\
\hline$A Y-102$ & $\longrightarrow$ C-104 & —C-103 \\
\hline AZ-101 & $\longrightarrow A Z-102$ & $-\mathrm{U}-110$ \\
\hline SY -102 & $\rightarrow$ Sludge, No-Flow Unsonicated & $\longrightarrow$ M2 Simulant \\
\hline
\end{tabular}

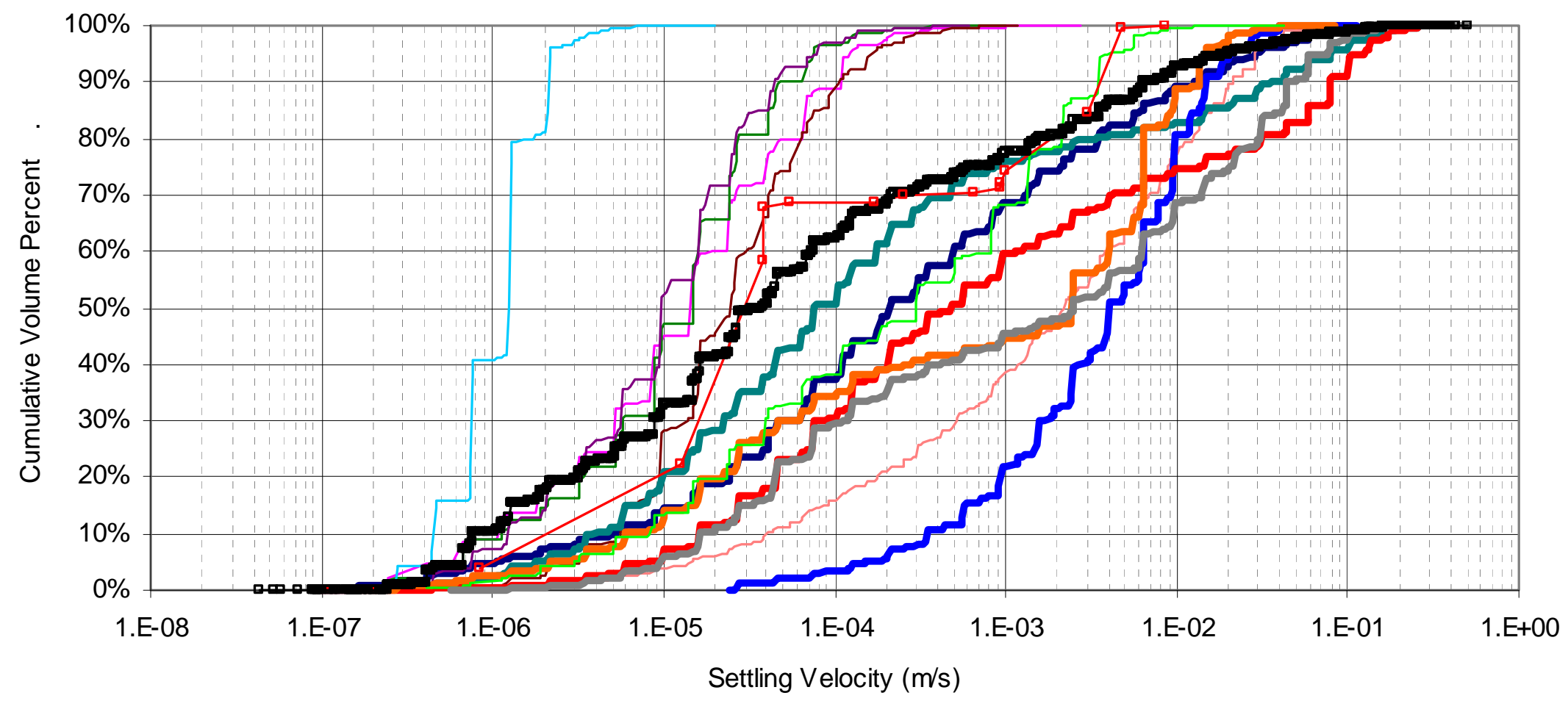

Figure 4.9. Settling Velocity Comparison. RPP-PLAN-44556, Rev. 2, "M2 Simulant," red line and square symbols; composite waste, black line and symbol. 


\begin{tabular}{|c|c|c|}
\hline$C-107$ & $-B X-107$ & - T-104 \\
\hline B-201 & - B-111 & $-\mathrm{T}-111$ \\
\hline AY-102 & $\longrightarrow \mathrm{C}-104$ & $\longrightarrow \mathrm{C}-103$ \\
\hline AZ-101 & $=A Z-102$ & $-\mathrm{U}-110$ \\
\hline SY-102 & $\rightarrow$ Sludge, No-Flow Unsonicated & $\longrightarrow$ M2 Simulant \\
\hline
\end{tabular}

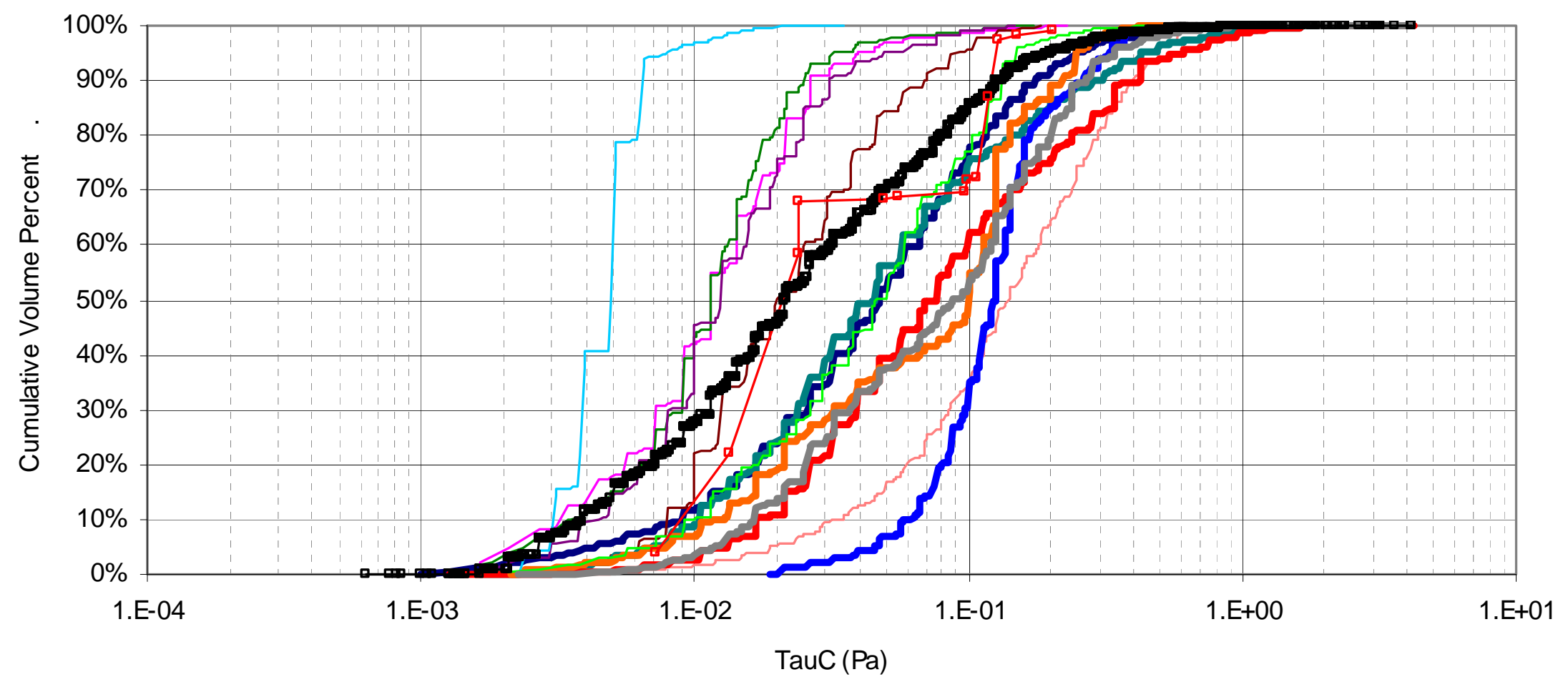

Figure 4.10. Critical Shear Stress for Erosion of Non-Cohesive Particles Comparison. RPP-PLAN-44556, Rev. 2, "M2 Simulant," red line and square symbols; composite waste, black line and symbol. 
In Figure 4.1 for abrasive wear of the Tefzel ${ }^{\circledR}$ valve seat, the RPP-PLAN-44556, Rev. 2, "M2 Simulant" is shown to be to the right of Sludge, No-Flow Unsonicated waste results (composite waste) up to approximately the $40^{\text {th }}$ percentile by volume, and to the left above that percentile. This observation indicates that the calculated abrasive wear of the minimally wearing $40 \%$ by volume of the simulant particulate is more challenging (i.e., higher wear rate) than the Sludge, No-Flow Unsonicated waste composite characterization. Similarly, the higher wearing $60 \%$ by volume of the simulant is less challenging than the composite, for example, more than two orders of magnitude less at the $90^{\text {th }}$ percentile. Even higher calculated wear rates on the Tefzel ${ }^{\circledR}$ seat are achieved for characterized wastes such as in tank C-104.

Similar results are achieved for the Kynar ${ }^{\circledR}$ and UHMWPE valve seats, Figure 4.2 and Figure 4.3 respectively, while the wear on the softer (see Table 3.1) stainless steel is relatively similar to the composite (Figure 4.4). Negligible wear is shown for both the simulant and the composite for the hard nickel plating (Figure 4.5). The critical transport velocity of the simulant is similar to the composite (Figure 4.6), while for the pipeline erosion rate comparison (Figure 4.7), the simulant is similar to the composite up to approximately the $80^{\text {th }}$ percentile, after which the erosion rate of the simulant is shown to be less. Similar results are achieved for the remaining metrics. In all cases, the simulant does not represent the more challenging characterized wastes. Thus, while the RPP-PLAN-44556, Rev. 2, "M2 Simulant" is shown to be generally similar for up to $80 \%$ by volume of the composite waste for metrics related to pipeline erosion (24590-WTP-TSP-RT-07-006, Rev. 2 references Gupta et al. (1995), see Section 2.3; Equation (2.5) does not account for particle hardness), it is not shown to be challenging with respect to the focus of DVI valve simulant testing abrasive wear.

\subsection{Simulant Adjustment}

Based on the comparison of the RPP-PLAN-44556, Rev. 2, specified DVI valve simulant and the Hanford Site waste presented in Section 4.1, the client requested an adjusted simulant be defined that matched the $75^{\text {th }}$ percentile by waste undissolved solid volume of the metrics. Specification for the $75^{\text {th }}$ percentile by volume target was provided as: ${ }^{1}$

- Testing of the DVI valves using simulants is to be performed to address aging failure effects specific to valve cycling to support the Safety-Significant Isolation Valves for Double Valve Isolation Functions and Requirements Evaluation Document and the DSA. The goal of the testing is to better determine a potential life span in terms of total cycles for valves, which perform DVI within the waste transfer system and provide a recommendation for routine equipment replacement.

- Simulant should be challenging to the valves/seats but not unrealistic as to what the waste transfer system will nominally see from waste transfers.

- M-2 Simulant recipes used by the WTP were evaluated and determined to be less challenging for valve surface abrasive wear in comparison to the composite slurry that represents a blending of all characterized tank sludge, Section 4.1.

- The composite is made up of all the characterized tanks which represent only $18 \%$ of the tank waste at the Hanford Site.

\footnotetext{
${ }^{1}$ E-mail communication from PA Gagnon, WRPS, to HE Adkins, PNNL, September 13, 2012.
} 
- The composite slurry provides metric results representing the blended waste including the least and most challenging of the characterized tank waste sludges. Therefore, although this represents a typical waste, it does not present a challenging test for the valves.

- A simulant that represents the metric results at $75 \%$ by volume would provide a simulant that is more challenging than the composite without being unrealistically challenging. The potential exists that test results may allow the prediction of valve performance under more aggressive simulants.

- The SSMD project has witnessed the negative consequences of utilizing the worst case simulants during testing. The test apparatus is subject to extreme wear and early failure which is non-representative of actual abrasive wear and erosion if the simulants were more realistic to the typical characterized sludge wastes.

The determination of the $75^{\text {th }}$ percentile by volume target is summarized in Section 4.2.1, and the adjusted simulant is developed in Section 4.2.2.

\subsubsection{Waste Target}

Determination of the $75^{\text {th }}$ percentile by solid volume target is described. Consider Figure 4.9, the settling velocity comparison results. Percentile values for the metric (in this example case, the particle settling velocity) are identified for each tank. For example, from Figure 4.9 at the $40^{\text {th }}$ percentile, the left-most curve, C-103, has a settling velocity of approximately $8 \mathrm{E}-6 \mathrm{~m} / \mathrm{s}$; the next curves to the right, BX-107, T-104, and T-111, $1 \mathrm{E}-5 \mathrm{~m} / \mathrm{s}$; and so on to the maximum curve at the $40^{\text {th }}$ percentile, C-104 at $\sim 3 \mathrm{E}-3 \mathrm{~m} / \mathrm{s}$. Each sludge waste tank represented in the figure contains a volume of undissolved solids (data from Wells et al. 2011 is used), therefore, each tank can represent a volume weighted fraction of the waste characterized. By sorting the $40^{\text {th }}$ percentile metric results in ascending order together with the fraction of waste by volume each result represents, a cumulative distribution of settling velocity results at the metric percentile ( $40^{\text {th }}$ percentile of the settling velocity for this example case) is created. The $75^{\text {th }}$ percentile result is then determined via linear interpolation from this cumulative distribution. In this example case, the result specifically represents the $75^{\text {th }}$ percentile by undissolved solid volume of the $40^{\text {th }}$ percentile of the settling velocity metric results. By repeating this process from the $0^{\text {th }}$ to $100^{\text {th }}$ percentile for each metric, a $75^{\text {th }}$ percentile by volume waste target for each metric is created. The results are labeled as " $75^{\text {th }}$ Percentile, UDS Volume" in the subsequent figures.

Each metric can provide different $75^{\text {th }}$ percentile by volume waste target results because of the different functionalities with the particle properties, Section 2. An example of this difference is comparison of the AY-102 metric results between Figure 4.1, Tefzel $^{\circledR}$ valve seat reference wear rate, and Figure 4.7, pipeline erosion rate. The volume contribution of the AY-102 metric result to the cumulative metric result at the $60^{\text {th }}$ percentile is at the maximum result in Figure 4.1, and is similar to the composite in Figure 4.7.

\subsubsection{Adjusted Simulant to Represent Waste Target}

A simulant is developed for the DVI valve testing that matches the selected $75^{\text {th }}$ percentile by volume waste target for each metric. The concentrations of potential simulant components are adjusted such that the calculated metric results for the simulant and target waste are concurrently similar (e.g., Lee et al. 2012). The potential simulant components are summarized and the adjusted DVI valve simulant results are presented. 
Potential simulant components are selected based on their representativeness of Hanford waste with respect to density, particle size, and hardness, as well as availability and cost. In addition to the currently available components of the RPP-PLAN-44556, Rev. 2, simulant described previously, the components of the Lee et al. (2012); 24590-WTP-RPT-RT-12-001, Rev. 0; and 24590-WTP-RPT-RT-12-002, Rev. 1, are also considered (Table 4.1). These simulant components were selected by teams comprised of WRPS, Bechtel National Inc., PNNL, and Energy Solutions staff with expert knowledge of Hanford waste undissolved solid properties and direct experience with Hanford waste simulant development and operations testing. Other factors taken into account in the selection of these simulant components included safety; equipment wear; staining of the equipment from materials such as iron oxide, which may inhibit visual observations; the ease or difficulty of analysis and the related costs; and the costs of disposal.

Table 4.1. Potential Simulant Components

\begin{tabular}{|c|c|c|c|c|c|c|}
\hline \multirow[b]{2}{*}{ Simulant } & \multirow[b]{2}{*}{ Component } & \multirow{2}{*}{$\begin{array}{l}\text { Crystal } \\
\text { Density } \\
(\mathrm{g} / \mathrm{mL})\end{array}$} & \multirow{2}{*}{$\begin{array}{c}\text { Mohs } \\
\text { Hardness }\end{array}$} & \multicolumn{3}{|c|}{$\begin{array}{l}\text { Approximate Percentile Particle Size } \\
\qquad(\mu \mathrm{m})^{(\mathrm{a})}\end{array}$} \\
\hline & & & & $1^{\text {st }}$ & $50^{\text {th }}$ & $99^{\text {th }}$ \\
\hline \multirow{12}{*}{ RPP-PLAN-44556 } & Almatis C-333 & 2.42 & 3 & 0.6 & 13 & 129 \\
\hline & Almatis C-31C & 2.42 & 3 & 6 & 60 & 129 \\
\hline & ZEO Z-Ultra & 2.15 & 3.75 & 0.5 & 28 & 167 \\
\hline & BASF HiQ-10 & 3.01 & 3.75 & 3 & 36 & 129 \\
\hline & Prince $\mathrm{Fe}_{2} \mathrm{O}_{3}$ & 5.24 & 5.5 & 0.2 & 1 & 13 \\
\hline & $\begin{array}{c}\text { Alfa Aesar } \\
\mathrm{Ca}_{5} \mathrm{OH}\left(\mathrm{PO}_{4}\right)_{3}\end{array}$ & 3.14 & 5 & 0.4 & 6 & 46 \\
\hline & Cerac $\mathrm{Bi}_{2} \mathrm{O}_{3}$ & 8.9 & 4.5 & 0.4 & 8 & 28 \\
\hline & Cerac $\mathrm{ZrO}_{2}$ & 5.68 & 6.5 & 1 & 17 & 46 \\
\hline & OK-110 & 2.65 & 7 & 60 & 100 & 129 \\
\hline & Aldrich $\mathrm{Ni}(\mathrm{OH})_{2}$ & 4.1 & 3.5 & 0.5 & 8 & 77 \\
\hline & Aldrich $\mathrm{MnO}_{2}$ & 5.03 & 6.25 & 2 & 36 & 129 \\
\hline & Aldrich $\mathrm{CaF}_{2}$ & 3.18 & 4 & 0.8 & 3 & 10 \\
\hline \multirow{6}{*}{ Lee et al. (2012) } & Small Gibbsite & 2.42 & 3.4 & 0.2 & 1 & 4 \\
\hline & Large Gibbsite & 2.42 & 3.4 & 0.3 & 9 & 34 \\
\hline & Small Sand & 2.65 & 6.5 & 0.6 & 34 & 200 \\
\hline & Large Sand & 2.65 & 6.5 & 133 & 394 & 679 \\
\hline & Zirconium Oxide & 5.7 & 8 & 0.4 & 13 & 262 \\
\hline & Stainless Steel & 8 & 5.5 & 4 & 59 & 262 \\
\hline \multirow{6}{*}{$\begin{array}{l}\text { 24590-WTP-RPT- } \\
\text { RT-12-001, } \\
\text { 24590-WTP-RPT- } \\
\text { RT-12-002 }\end{array}$} & SiC F-1000 Powder & 3.2 & 9.5 & 0.4 & 5 & 11 \\
\hline & W-121 Powder & 9.6 & 6.7 & 3 & 16 & 36 \\
\hline & Glass Powder & 2.9 & 6.5 & 40 & 100 & 224 \\
\hline & Alumina & 4 & 9 & 224 & 399 & 710 \\
\hline & Grout & 2.6 & 7 & 448 & 796 & 1589 \\
\hline & Glass beads & 2.5 & 6.5 & 796 & 1002 & 1416 \\
\hline \multicolumn{7}{|c|}{$\begin{array}{l}\text { (a) Particle-size distributions for RRP-PLAN-44556, Rev. 2, approximated from 24590-QL-HC4-W000-00076-02- } \\
\text { 00003, Rev. 00A; Lee et al. (2012), e-mail communication from KP Lee, WRPS, to CA Burns and BE Wells, } \\
\text { PNNL; and 24590-WTP-RPT-RT-12-001, Rev. } 0 \text { and 24590-WTP-RPT-RT-12-002, Rev. 1, from } \\
\text { CCP-WTPSP-1155. Percentiles are approximated from cumulative distributions. }\end{array}$} \\
\hline
\end{tabular}


The bases for selecting the components and concentrations for the DVI slurry simulant are the primary metrics listed in Section 2 describing valve surface abrasion due to particle interaction as well as secondary metrics for pipeline transfer and erosion as the slurry is flowing through the piping, particle settling under conditions of no flow, and particle suspension for conditions of re-establishing flow. As previously described, adjustment of potential simulant component concentrations is made such that the calculated simulant and the waste target for the majority of the metrics are concurrently similar. Valve abrasive metrics are given highest priority for similarity using the components listed in Table 4.1.

Figure 4.11 through Figure 4.20 show the comparison of the adjusted simulant, denoted as "Recommended Simulant" and the light green line and large square symbols, to actual waste data for the metrics. The " $75^{\text {th }}$ Percentile, UDS Volume" described in Section 4.2.1 is identified by the bold pink line and square symbols. The composition of the Recommended Simulant is provided in Table 4.2. The average undissolved solid density of this composition is approximately $3.17 \mathrm{~g} / \mathrm{mL}$.

Table 4.2. Recommended DVI Valve Test Simulant

\begin{tabular}{|c|c|c|c|c|c|c|c|c|}
\hline \multirow[b]{2}{*}{ Component } & \multirow[b]{2}{*}{ Supplier, Product ID } & \multirow{2}{*}{$\begin{array}{l}\text { Crystal } \\
\text { Density } \\
(\mathrm{g} / \mathrm{mL})\end{array}$} & \multirow{2}{*}{$\begin{array}{l}\text { Mohs } \\
\text { Hardness }\end{array}$} & \multirow{2}{*}{$\begin{array}{l}\text { Volume } \\
\text { Fraction }\end{array}$} & \multirow{2}{*}{$\begin{array}{l}\text { Mass } \\
\text { Fraction }\end{array}$} & \multicolumn{3}{|c|}{$\begin{array}{c}\text { Approximate Percentile } \\
\text { Particle Size }(\mu \mathrm{m})\end{array}$} \\
\hline & & & & & & $1^{\mathrm{st}}$ & $50^{\text {th }}$ & $90^{\text {th }}$ \\
\hline Gibbsite $^{(a)}$ & $\begin{array}{c}\text { READE Advanced } \\
\text { Materials, Huber, Onyx } \\
\text { Elite } 103\end{array}$ & 2.42 & 3 & 0.24 & 0.186 & 7.4 & 80 & 158 \\
\hline Zeolite $^{(\mathrm{b})}$ & ZEO Inc., ZAR-MIN ${ }^{\circledR}$ & 2.15 & 3.75 & 0.18 & 0.124 & 4.7 & 53 & 309 \\
\hline $\mathrm{Ca}_{5} \mathrm{OH}\left(\mathrm{PO}_{4}\right)_{3}{ }^{(\mathrm{c})}$ & $\begin{array}{l}\text { READE Advanced } \\
\text { Materials, Jost, Tribasic } \\
\text { Calcium Phosphate }\end{array}$ & 3.14 & 5 & 0.12 & 0.120 & 1.0 & 4.7 & 12 \\
\hline $\mathrm{Bi}_{2} \mathrm{O}_{3}{ }^{(\mathrm{d})}$ & $\begin{array}{l}\text { READE Advanced } \\
\text { Materials, Ferro, } 320 \\
\text { Bismuth Trioxide }\end{array}$ & 8.9 & 4.5 & 0.02 & 0.057 & 2.6 & 8.7 & 24 \\
\hline Boehmite ${ }^{(\mathrm{e})}$ & $\begin{array}{c}\text { READE Advanced } \\
\text { Materials, } \\
\text { NALBALTEC, AOH20 }\end{array}$ & 3.01 & 4 & 0.22 & 0.212 & 2.2 & 8.5 & 21 \\
\hline Large Gibbsite & $\begin{array}{c}\text { READE Advanced } \\
\text { Materials, Huber, Onxy } \\
\text { Elite } 431\end{array}$ & 2.42 & 3.4 & 0.08 & 0.062 & 0.3 & 8.8 & 20 \\
\hline Large Sand & $\begin{array}{l}\text { READE Advanced } \\
\text { Materials, US Silica } \\
\text { (Mauricetown NJ6) }\end{array}$ & 2.65 & 6.5 & 0.03 & 0.025 & 133 & 394 & 592 \\
\hline $\begin{array}{l}\text { Zirconium } \\
\text { Oxide }\end{array}$ & $\begin{array}{l}\text { Washington Mills, } \\
\text { Durazon MCG } 360\end{array}$ & 5.7 & 8 & 0.09 & 0.164 & 0.4 & 13 & 30 \\
\hline Stainless Steel & $\begin{array}{l}\text { Pellets LLC, } \\
\text { PWDR - 150S }\end{array}$ & 8 & 5.5 & 0.02 & 0.051 & 4.5 & 59 & 152 \\
\hline \\
\hline $\begin{array}{l}\text { (b) Replacemen } \\
\text { ZEO Inc., N } \\
\text { (c) Replacemen } \\
\text { (d) Replacemen } \\
\text { (e) Replacemen }\end{array}$ & $\begin{array}{l}\text { It component for ZEO Z-U } \\
\text { IcKinney, Texas. } \\
\text { it component for Alfa Aesa } \\
\text { t component for Cerac } \mathrm{Bi}_{2} \\
\text { it component for Aldrich }\end{array}$ & $\begin{array}{l}\text { tra. PSD f } \\
\mathrm{Ca}_{5} \mathrm{OH}(\mathrm{P} \\
\mathrm{F}_{2} \text {. PSD } \mathrm{PSD}\end{array}$ & $\begin{array}{l}\text { rom TDP-D } \\
\left.\mathrm{O}_{4}\right)_{3} \text {. PSD } \\
\text { om TDP-D } \\
\text { rom TDP-D }\end{array}$ & $\begin{array}{l}\text { VI-001. Z } \\
\text { rom TDP- } \\
\text { I-001. } \\
\text { VI-001. }\end{array}$ & $\begin{array}{l}\text { AR-MIN is } \\
\text { VI-001. }\end{array}$ & regis & trade & rk of \\
\hline
\end{tabular}


The comparison of the relative wear rates for the Recommended Simulant on the Tefzel ${ }^{\circledR}$, Kynar $^{\circledR}$, and UHMWPE valve seat surfaces is similar to the $75^{\text {th }}$ Percentile waste target for the negligible relative wear rates (below 0.001) up to the maximum relative wear rates (Figure 4.11 through Figure 4.13). An exact match was not possible within the range of simulants referenced in Table 4.1 or available replacement components with similar characteristics (Table 4.2). For the stainless steel ball (Figure 4.14), the Recommended Simulant exceeds the reference wear rate target from the negligible wear rates and up to approximately 0.3 (70\% of the simulant by volume) and is then similar for the higher relative wear rates. The simulant does not exceed the characterized waste for this metric. From Figure 4.15 for the nickel plated ball, the $90 \%$ by volume of the Recommended Simulant is similar to the waste target for negligible relative wear rates, and the remainder of the simulant exceeds the target. However, given the relative hardness of the nickel plating (Section 3) and resultant low relative wear rates (i.e., less than 0.4 of the maximum), this exceedance, which cannot be avoided with the current list of components while still matching the other metrics (e.g., Figure 4.11 through Figure 4.14), is not viewed as problematic. The simulant is shown to agree reasonably well with the waste target with for all of the pipeline metrics (Figure 4.16 through Figure 4.20).

A summary of the metric comparisons for the waste target and recommended simulant is provided in Table 4.3. The Recommended Simulant is similar to the $75^{\text {th }}$ Percentile waste target for 8 of the 10 metrics. For the two metrics that relate to valve ball surface relative abrasive wear, a fraction of the simulant is more challenging as previously discussed.

Table 4.3. Metric Comparison Summary

\begin{tabular}{|c|c|c|}
\hline Metric & Figure Reference & Comparison \\
\hline $\begin{array}{l}\text { Tefzel }^{\circledR} \text { valve surface relative abrasive wear } \\
\text { rate }\end{array}$ & Figure 4.11 & $\mathrm{~S}$ \\
\hline $\begin{array}{l}\text { Kynar }{ }^{\circledR} \text { valve surface relative abrasive wear } \\
\text { rate }\end{array}$ & Figure 4.12 & $\mathrm{~S}$ \\
\hline $\begin{array}{l}\text { UHMWPE valve surface relative abrasive } \\
\text { wear rate }\end{array}$ & Figure 4.13 & S \\
\hline $\begin{array}{l}\text { Stainless steel valve surface relative abrasive } \\
\text { wear rate }\end{array}$ & Figure 4.14 & $\mathrm{MC}$ \\
\hline $\begin{array}{l}\text { Nickel plating valve surface relative abrasive } \\
\text { wear rate }\end{array}$ & Figure 4.15 & $\mathrm{MC}$ \\
\hline Pipeline critical transport velocity, $\mathrm{U}_{\mathrm{C}}(\mathrm{m} / \mathrm{s})$ & Figure 4.16 & $\mathrm{~S}$ \\
\hline Pipeline erosion rate, $\mathrm{E}_{\text {pipe }}(\mathrm{mm} / \mathrm{yr})$ & Figure 4.17 & S \\
\hline Archimedes number, Ar & Figure 4.18 & $\mathrm{~S}$ \\
\hline Settling velocity, $U_{\mathrm{T}}(\mathrm{m} / \mathrm{s})$ & Figure 4.19 & $\mathrm{~S}$ \\
\hline $\begin{array}{l}\text { Critical shear stress for erosion of } \\
\text { non-cohesive particles, } \tau_{\mathrm{c}}(\mathrm{Pa})\end{array}$ & Figure 4.20 & $\mathrm{~S}$ \\
\hline \multicolumn{3}{|c|}{$\begin{array}{l}\mathrm{S}=\text { Waste target and simulant are relatively similar. } \\
\mathrm{MC}=\text { Simulant is relatively more challenging than a fraction of the waste target }(\sim 10 \% \\
\quad \text { by volume at a given metric value }) .\end{array}$} \\
\hline
\end{tabular}




\begin{tabular}{|lll|}
\hline $\begin{array}{lll}- \text { C-107 } \\
\text { B-201 }\end{array}$ & - T-104 \\
\hline AY-102 & B-111 & T-111 \\
AZ-101 & C-103 \\
- SY-102 & - AZ-102 & U-110 \\
$\square$ - S5th Percentile, UDS Volume & - Recommended Simulant & \\
\hline
\end{tabular}

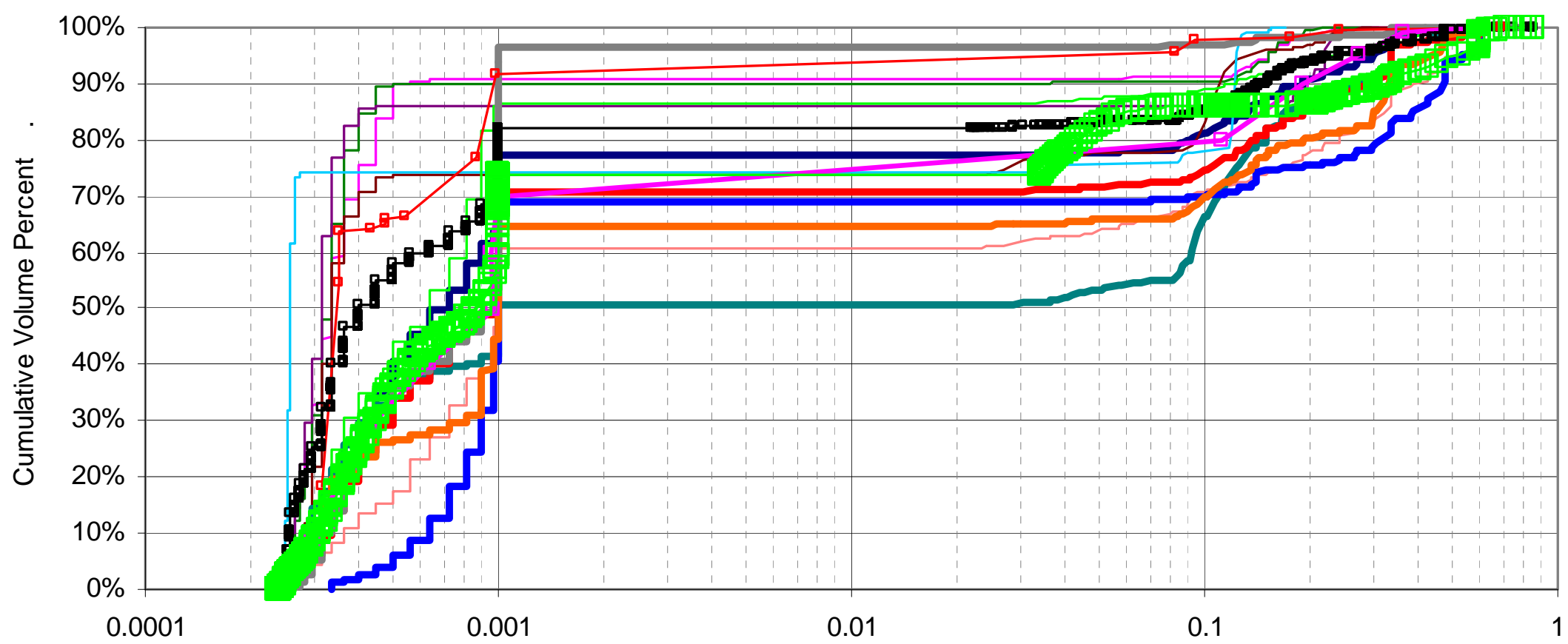

Tefzel (Wear Rate/Reference Wear Rate)Hardness X (Wear Rate/Reference Wear Rate)Diameter

Figure 4.11. Tefzel ${ }^{\circledR}$ Valve Seat Reference Wear Rate Comparison. Recommended Simulant, light green line and large square symbols; $75^{\text {th }}$ Percentile, UDS Volume, bold pink line and square symbols; RPP-PLAN-44556, Rev. 2, "M2 Simulant," red line and square symbols; composite waste, black line and symbol. 


\begin{tabular}{|c|c|c|}
\hline$C-107$ & BX-107 & $-\mathrm{T}-104$ \\
\hline B-201 & - B-111 & $-\mathrm{T}-111$ \\
\hline AY -102 & $\mathrm{C}-104$ & $-\mathrm{C}-103$ \\
\hline AZ-101 & $-A Z-102$ & $-\mathrm{U}-110$ \\
\hline SY -102 & $\longrightarrow$ Sludge, No-Flow Unsonicated & $\longrightarrow \mathrm{M} 2$ Simulant \\
\hline — 75th Percentile, UDS Volume & $\square$-Recommended Simulant & \\
\hline
\end{tabular}

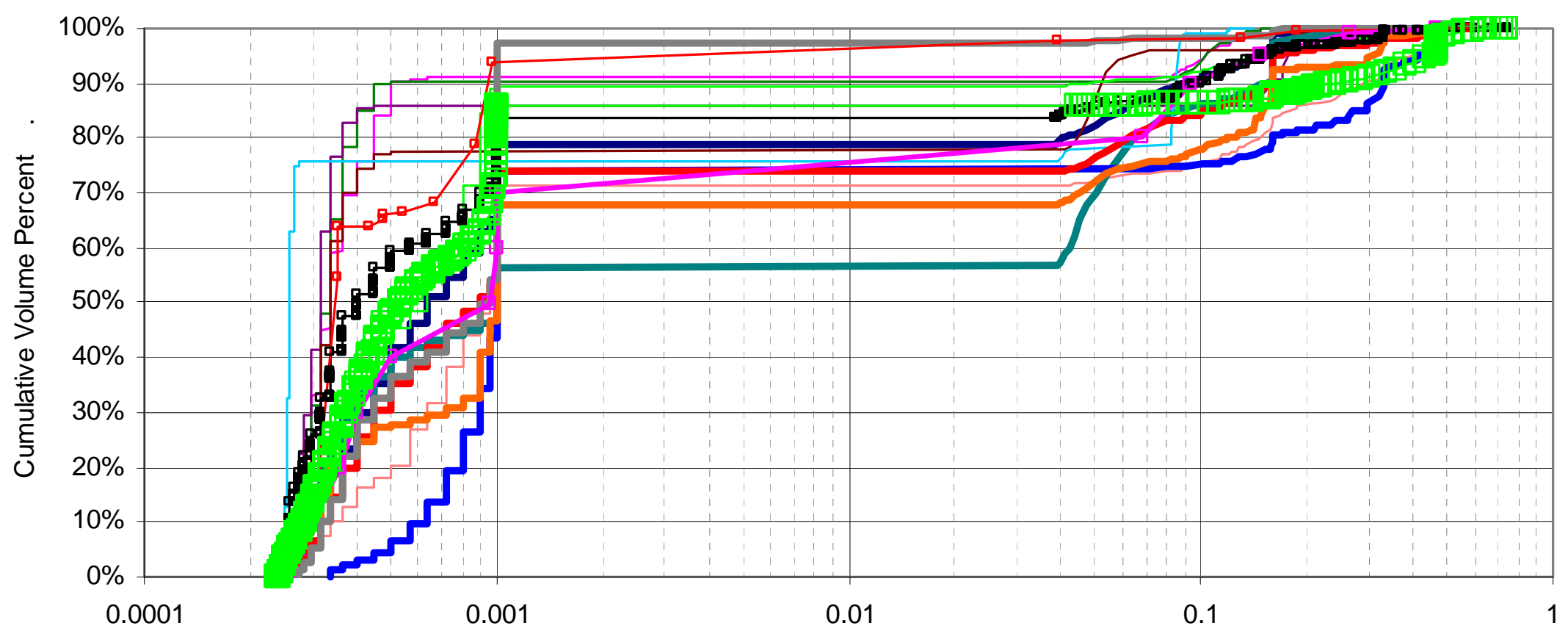

Kynar (Wear Rate/Reference Wear Rate)Hardness X (Wear Rate/Reference Wear Rate)Diameter

Figure 4.12. Kynar $^{\circledR}$ Valve Seat Reference Wear Rate Comparison. Recommended Simulant, light green line and large square symbols; $75^{\text {th }}$ Percentile, UDS Volume, bold pink line and square symbols; RPP-PLAN-44556, Rev. 2, "M2 Simulant," red line and square symbols; composite waste, black line and symbol. 


\begin{tabular}{|c|c|c|}
\hline $\mathrm{C}-107$ & BX-107 & $-\mathrm{T}-104$ \\
\hline B-201 & B-111 & $-\mathrm{T}-111$ \\
\hline$\longrightarrow A Y-102$ & $\longrightarrow \mathrm{C}-104$ & $-\mathrm{C}-103$ \\
\hline AZ-101 & $A Z-102$ & $-\mathrm{U}-110$ \\
\hline SY-102 & $\longrightarrow$ Sludge, No-Flow Unsonicated & $\longrightarrow \mathrm{M} 2$ Simulant \\
\hline$\square$ - 75th Percentile, UDS Volume & $\square-$ Recommended Simulant & \\
\hline
\end{tabular}

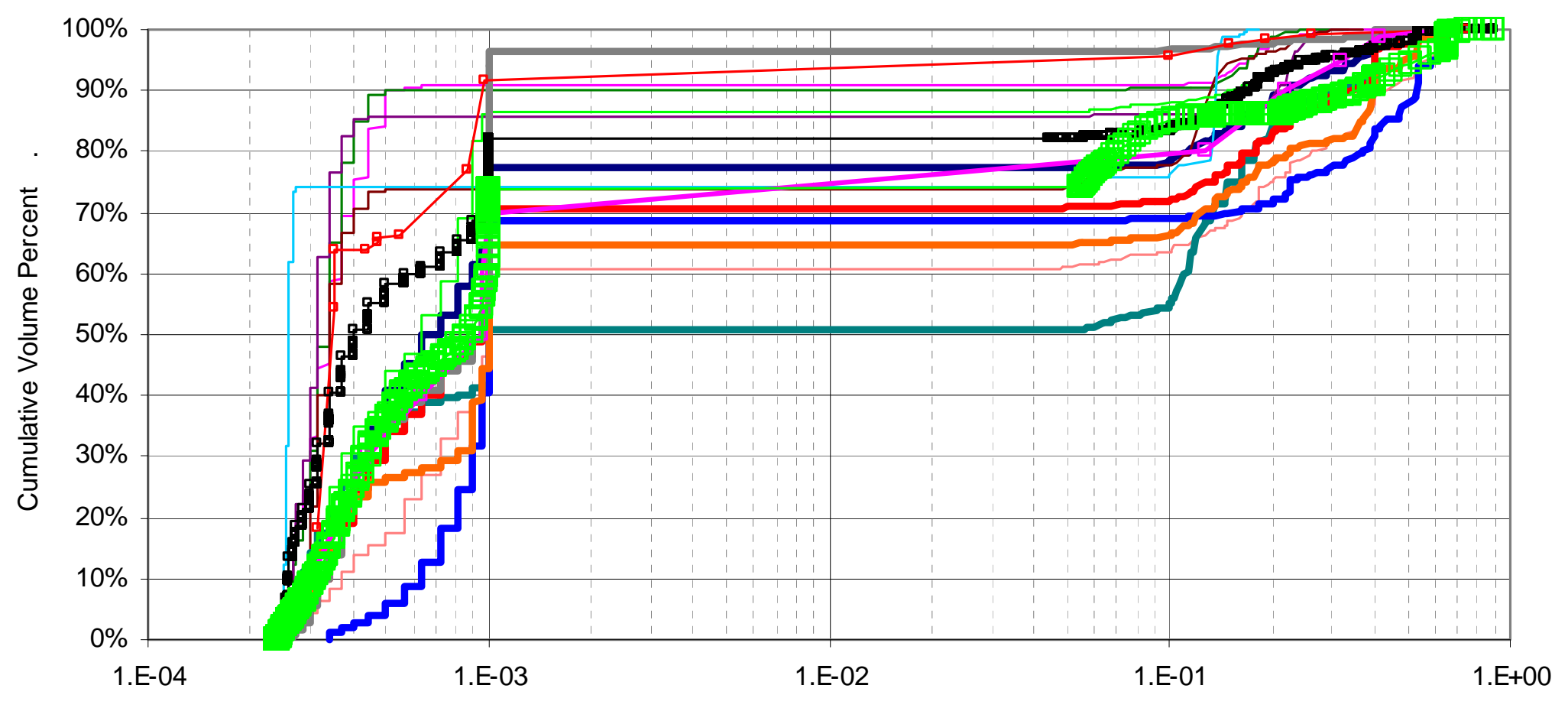

UHMWPE (Wear Rate/Reference Wear Rate)Hardness X (Wear Rate/Reference Wear Rate)Diameter

Figure 4.13. UHMWPE Valve Seat Reference Wear Rate Comparison. Recommended Simulant, light green line and large square symbols; $75^{\text {th }}$ Percentile, UDS Volume, bold pink line and square symbols; RPP-PLAN-44556, Rev. 2, "M2 Simulant," red line and square symbols; composite waste, black line and symbol. 


\begin{tabular}{|c|c|c|}
\hline $\mathrm{C}-107$ & $-\mathrm{BX}-107$ & $-\mathrm{T}-104$ \\
\hline - B-201 & - B-111 & $-\mathrm{T}-111$ \\
\hline$\longrightarrow \mathrm{AY}-102$ & $\longrightarrow \mathrm{C}-104$ & $-\mathrm{C}-103$ \\
\hline AZ-101 & $\longrightarrow$ AZ-102 & $-\mathrm{U}-110$ \\
\hline SY-102 & $\longrightarrow$ Sludge, No-Flow Unsonicated & $\longrightarrow$ M2 Simulant \\
\hline$\because 75$ th Percentile, UDS Volume & $\square$ Recommended Simulant & \\
\hline
\end{tabular}

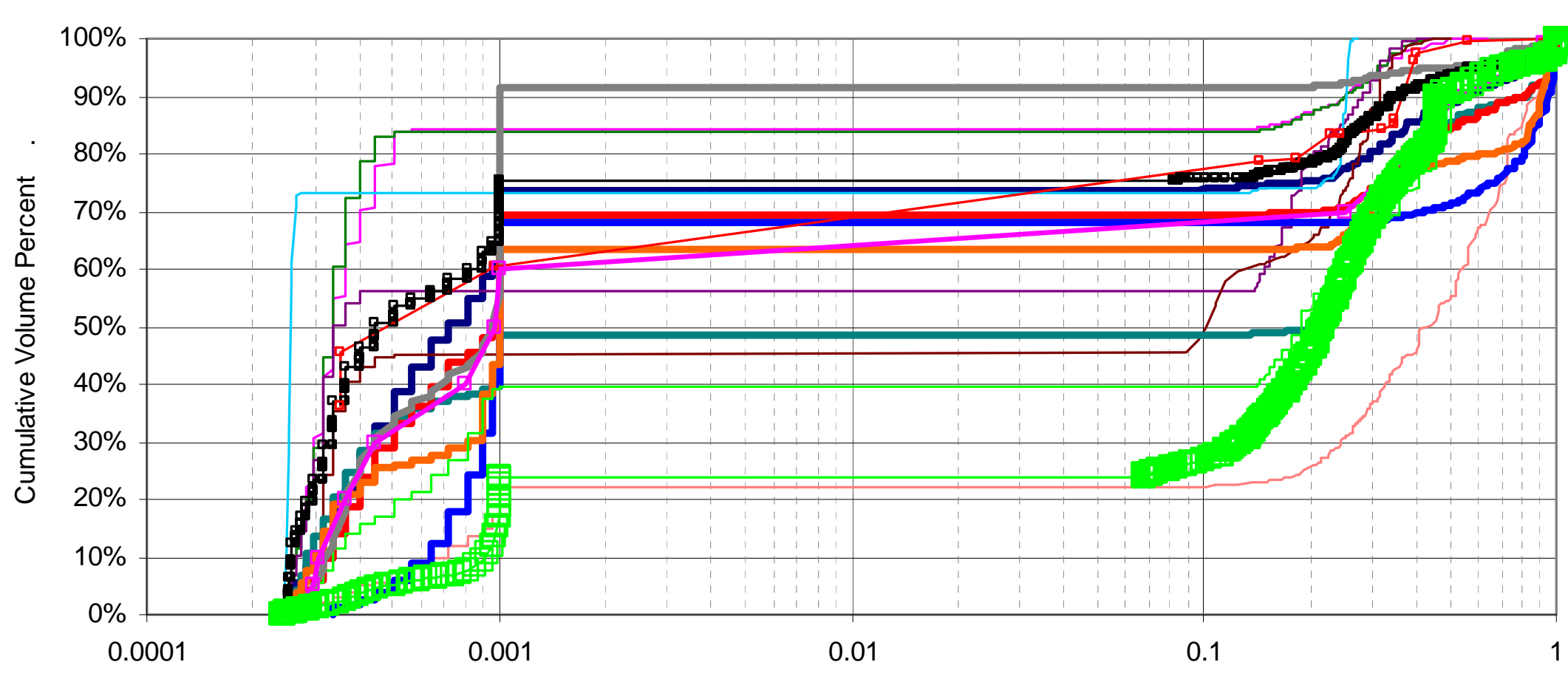

SS (Wear Rate/Reference Wear Rate)Hardness X (Wear Rate/Reference Wear Rate)Diameter

Figure 4.14. Stainless Steel Valve Ball Reference Wear Rate Comparison. Recommended Simulant, light green line and large square symbols; $75^{\text {th }}$ Percentile, UDS Volume, bold pink line and square symbols; RPP-PLAN-44556, Rev. 2, "M2 Simulant," red line and square symbols; composite waste, black line and symbol. 


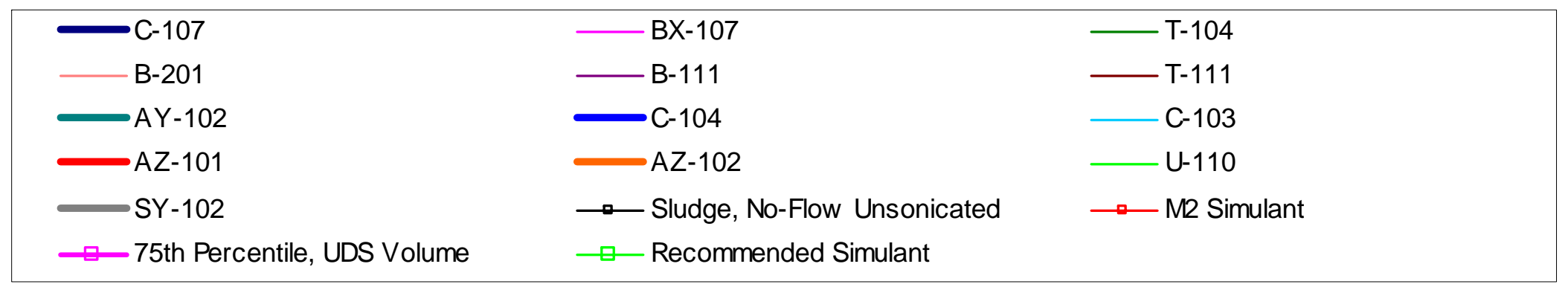

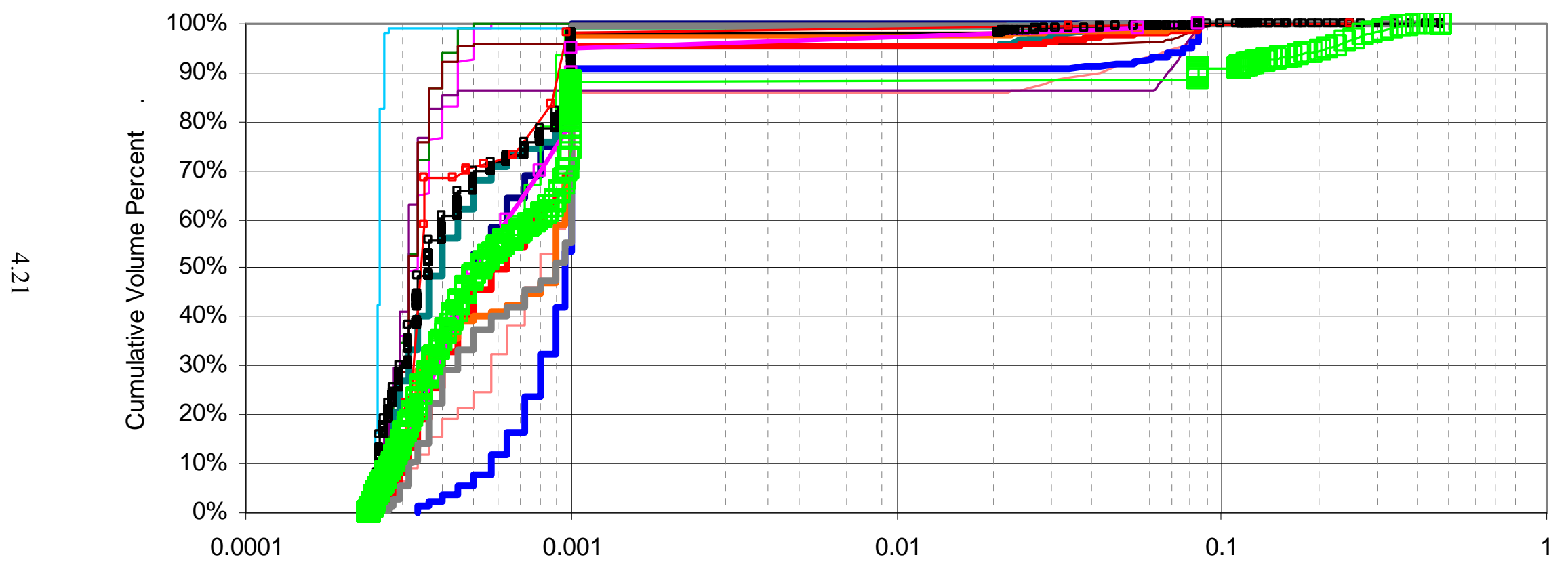

Nickel Plating (Wear Rate/Reference Wear Rate)Hardness X (Wear Rate/Reference Wear Rate)Diameter

Figure 4.15. Nickel Plating Valve Ball Reference Wear Rate Comparison. Recommended Simulant, light green line and large square symbols; $75^{\text {th }}$ Percentile, UDS Volume, bold pink line and square symbols; RPP-PLAN-44556, Rev. 2, "M2 Simulant," red line and square symbols; composite waste, black line and symbol. 


\begin{tabular}{|c|c|c|}
\hline $\mathrm{C}-107$ & $-\mathrm{BX}-107$ & $-\mathrm{T}-104$ \\
\hline B-201 & B-111 & $\longrightarrow \mathrm{T}-111$ \\
\hline AY-102 & $\longrightarrow$ C-104 & $-\mathrm{C}-103$ \\
\hline AZ-101 & $\longrightarrow \mathrm{AZ}-102$ & $-\mathrm{U}-110$ \\
\hline SY-102 & $\longrightarrow$ Sludge, No-Flow Unsonicated & $\longrightarrow \mathrm{M} 2$ Simulant \\
\hline$\square$-75th Percentile, UDS Volume & $\square$ Recommended Simulant & \\
\hline
\end{tabular}

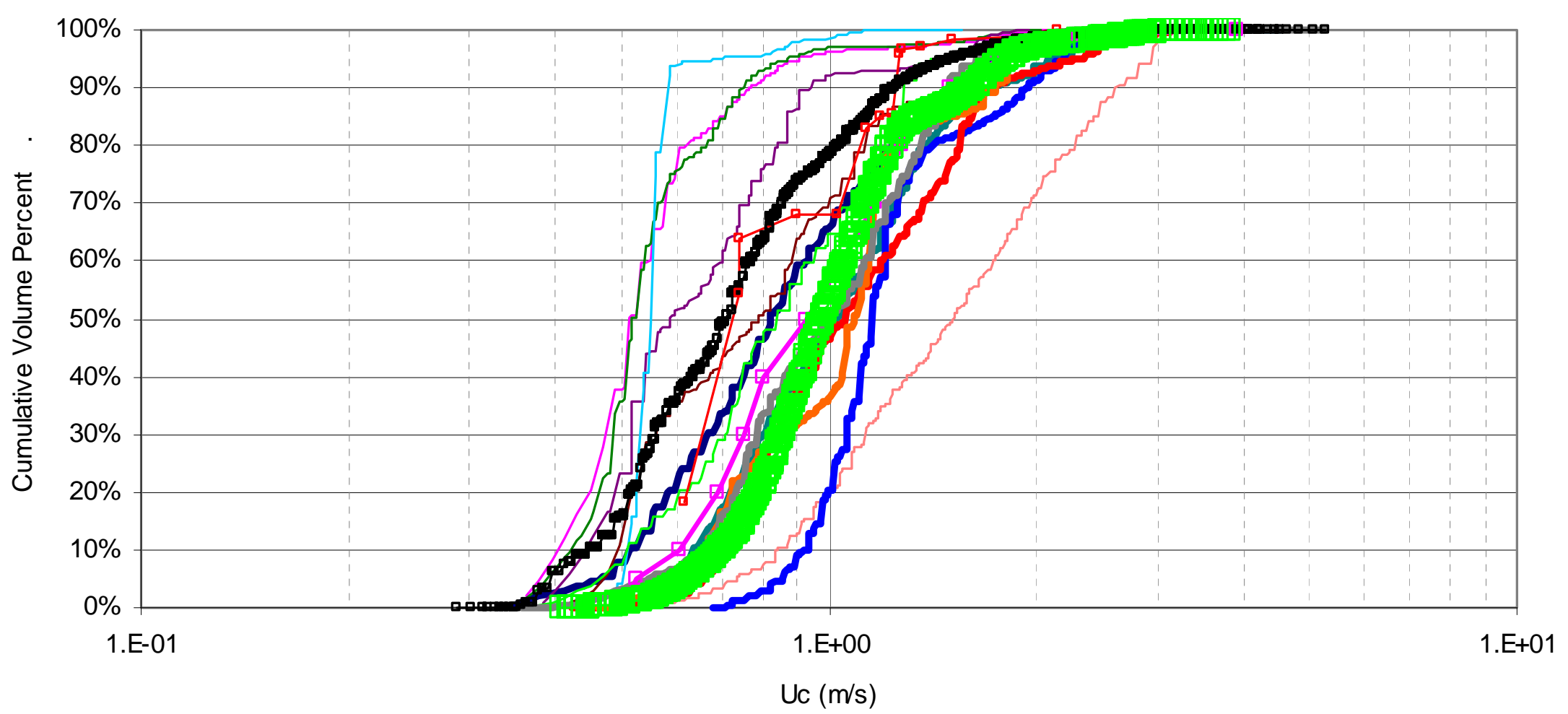

Figure 4.16. Pipeline Critical Transport Velocity Comparison. Recommended Simulant, light green line and large square symbols; $75^{\text {th }}$ Percentile, UDS Volume, bold pink line and square symbols; RPP-PLAN-44556, Rev. 2, "M2 Simulant," red line and square symbols; composite waste, black line and symbol. 


\begin{tabular}{|c|c|c|}
\hline $\mathrm{C}-107$ & BX-107 & $-\mathrm{T}-104$ \\
\hline B-201 & - B-111 & $-\mathrm{T}-111$ \\
\hline$\longrightarrow$ AY -102 & C-104 & $-\mathrm{C}-103$ \\
\hline AZ-101 & AZ-102 & U-110 \\
\hline SY-102 & $\longrightarrow$ Sludge, No-Flow Unsonicated & $\longrightarrow$ M2 Simulant \\
\hline$\square$-75th Percentile, UDS Volume & $\square-$ Recommended Simulant & \\
\hline
\end{tabular}

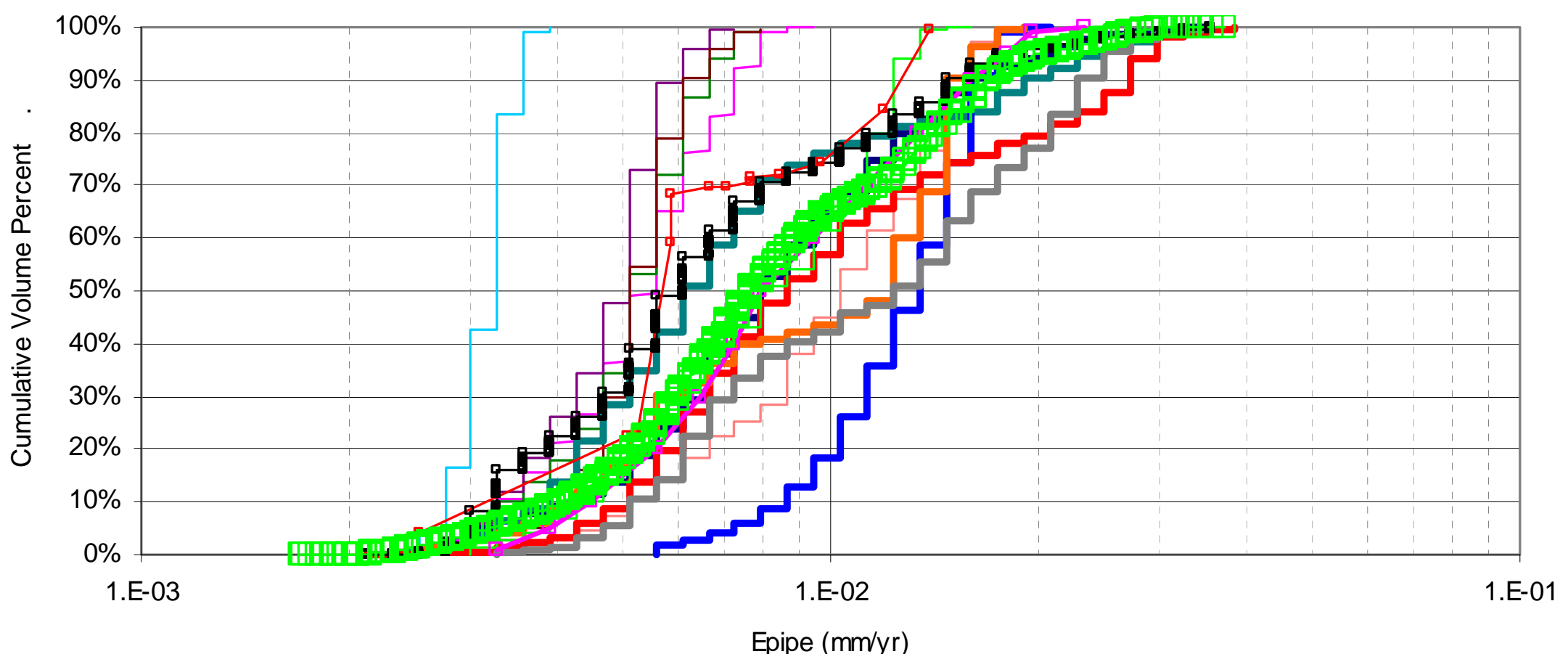

Figure 4.17. Pipeline Erosion Rate Comparison. Recommended Simulant, light green line and large square symbols; $75^{\text {th }}$ Percentile, UDS Volume, bold pink line and square symbols; RPP-PLAN-44556, Rev. 2, "M2 Simulant," red line and square symbols; composite waste, black line and symbol. 


\begin{tabular}{|c|c|c|}
\hline $\mathrm{C}-107$ & BX-107 & $-\mathrm{T}-104$ \\
\hline B-201 & B-111 & - T-111 \\
\hline AY -102 & C-104 & C-103 \\
\hline AZ-101 & AZ-102 & $\longrightarrow$ U-110 \\
\hline SY-102 & $\rightarrow$ Sludge, No-Flow Unsonicated & $\longrightarrow \mathrm{M} 2$ Simulant \\
\hline
\end{tabular}

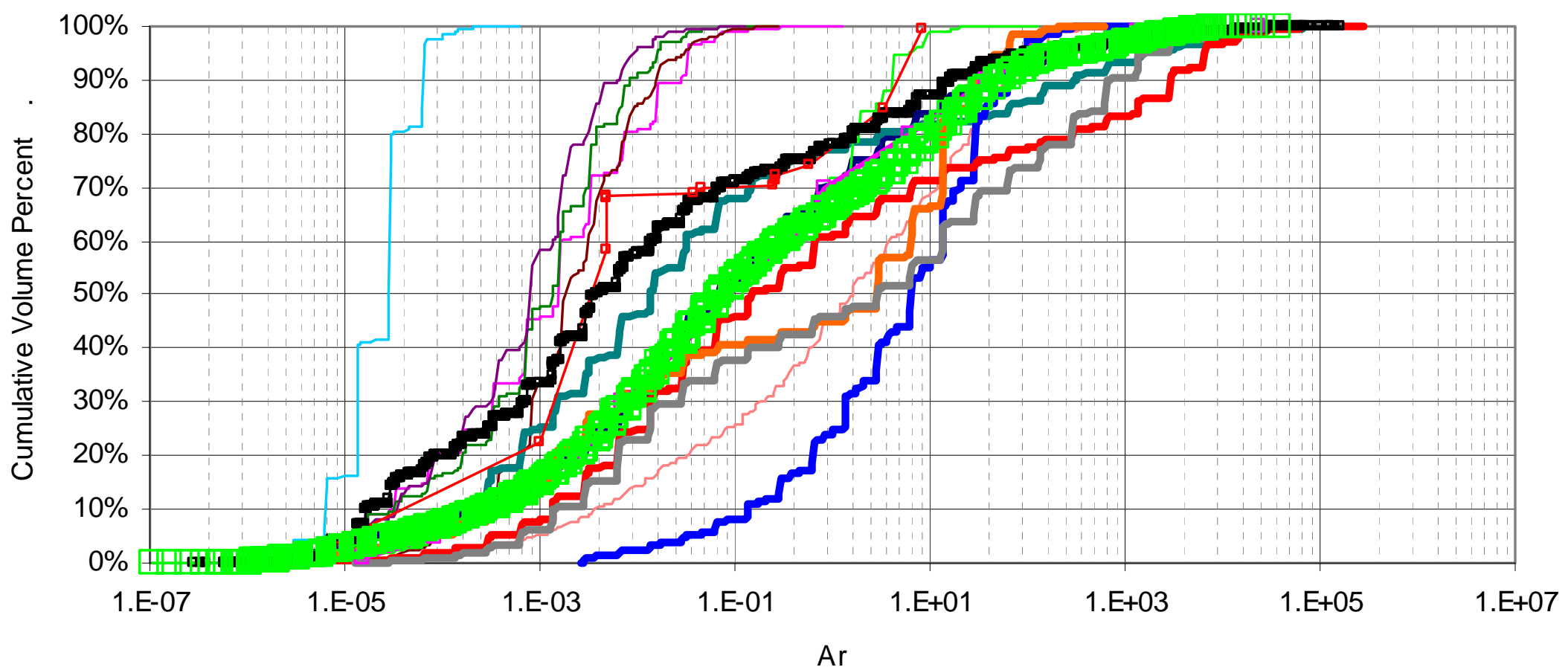

Figure 4.18. Archimedes Number Comparison. Recommended Simulant, light green line and large square symbols; $75^{\text {th }}$ Percentile, UDS Volume, bold pink line and square symbols; RPP-PLAN-44556, Rev. 2, "M2 Simulant," red line and square symbols; composite waste, black line and symbol. 


\begin{tabular}{|c|c|c|}
\hline $\mathrm{C}-107$ & BX-107 & $-\mathrm{T}-104$ \\
\hline - B-201 & - B-111 & $-\mathrm{T}-111$ \\
\hline$\longrightarrow A Y-102$ & $\longrightarrow \mathrm{C}-104$ & $-\mathrm{C}-103$ \\
\hline AZ-101 & AZ-102 & $-\mathrm{U}-110$ \\
\hline SY-102 & $\rightarrow$ Sludge, No-Flow Unsonicated & $\longrightarrow \mathrm{M} 2$ Simulant \\
\hline$\square$ 75th Percentile, UDS Volume & $\square$ Recommended Simulant & \\
\hline
\end{tabular}

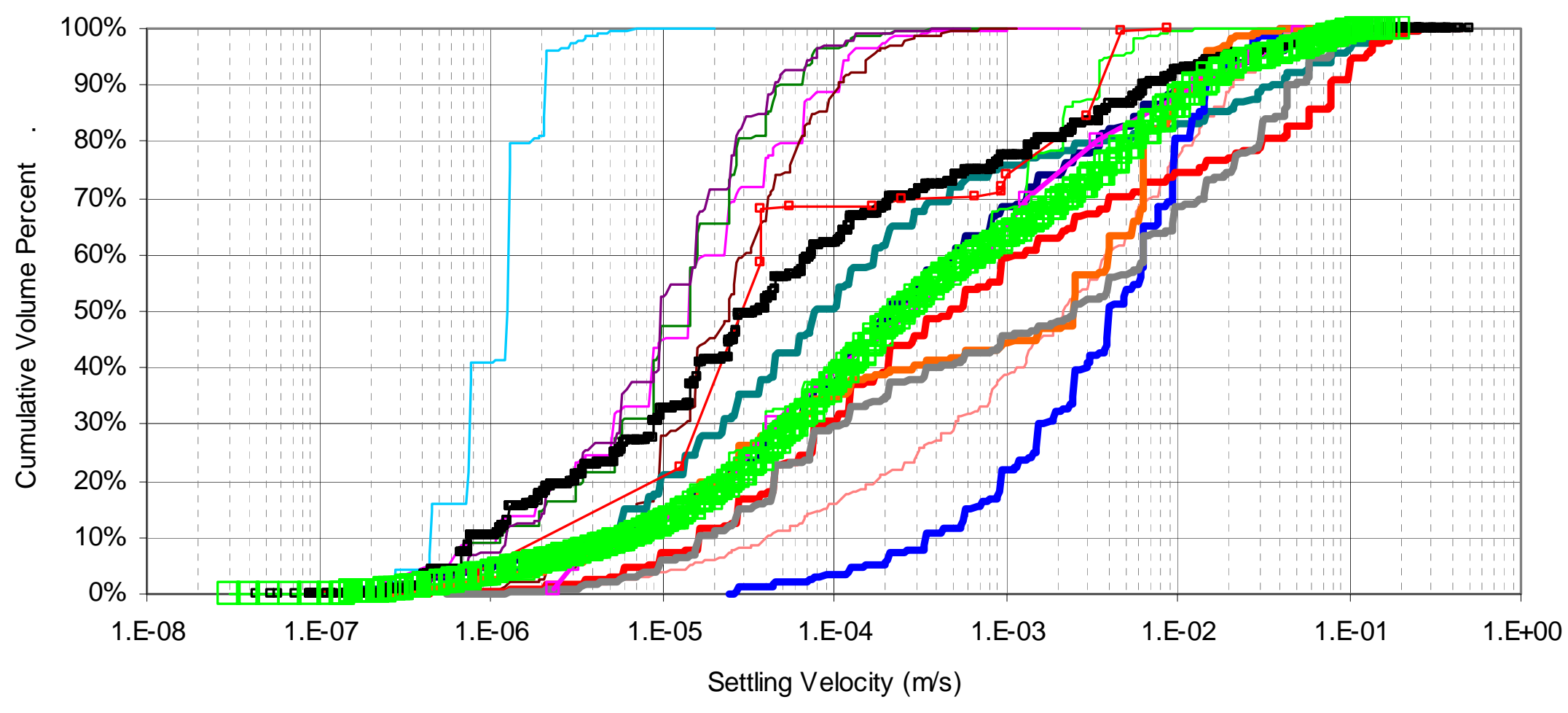

Figure 4.19. Settling Velocity Comparison. Recommended Simulant, light green line and large square symbols; $75^{\text {th }}$ Percentile, UDS Volume, bold pink line and square symbols; RPP-PLAN-44556, Rev. 2, "M2 Simulant," red line and square symbols; composite waste, black line and symbol. 


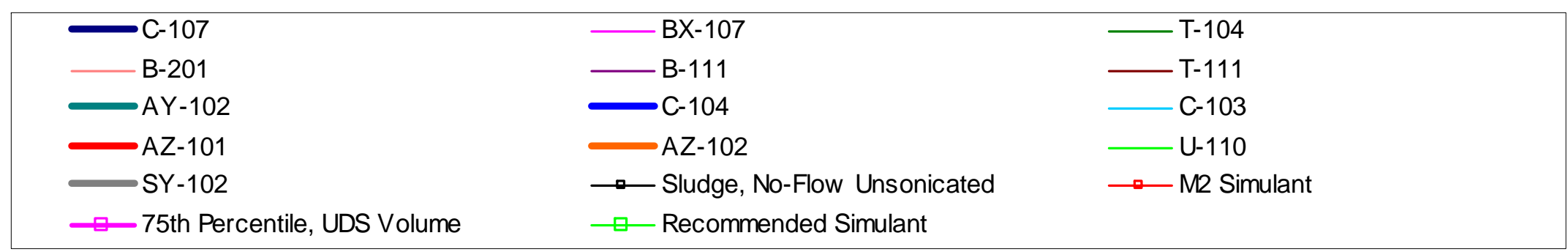

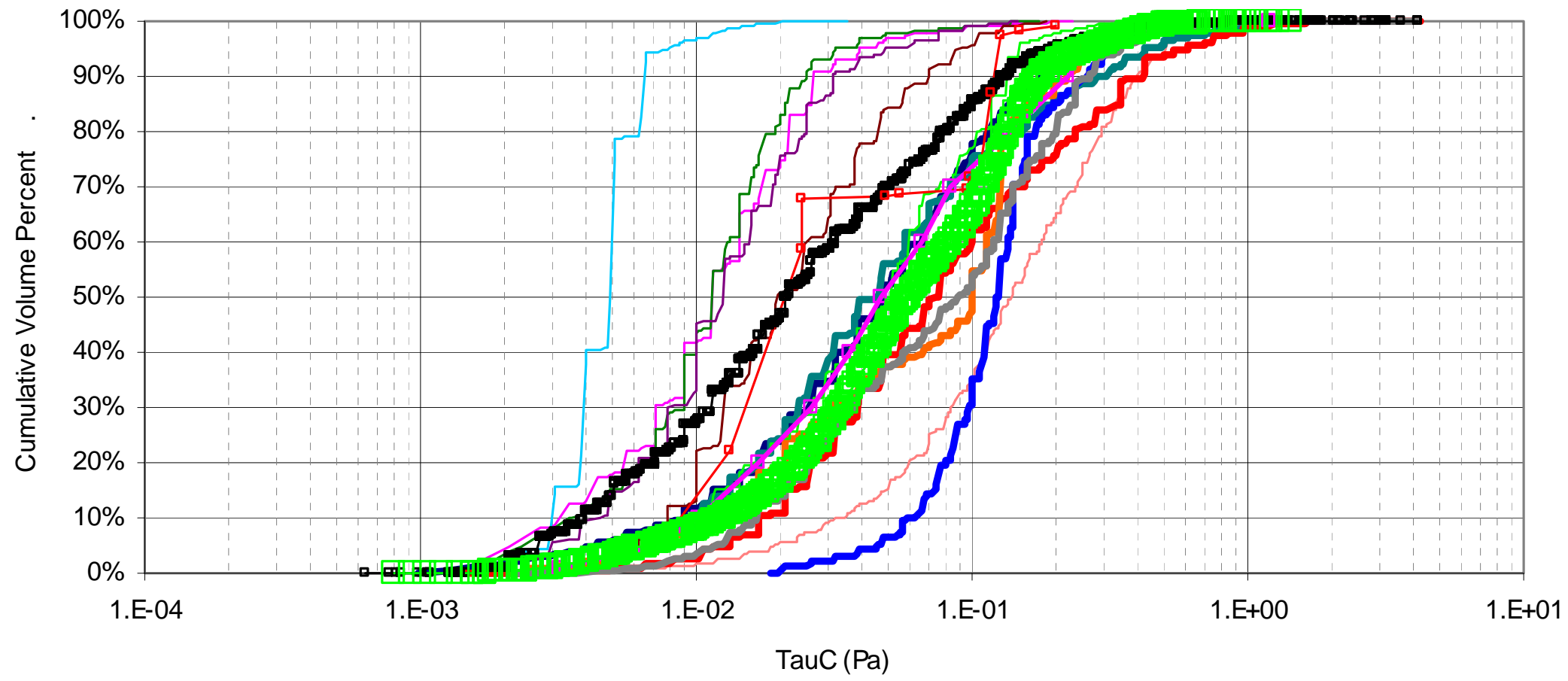

Figure 4.20. Critical Shear Stress for Erosion of Non-Cohesive Particles Comparison. Recommended Simulant, light green line and large square symbols; $75^{\text {th }}$ Percentile, UDS Volume, bold pink line and square symbols; RPP-PLAN-44556, Rev. 2, "M2 Simulant," red line and square symbols; composite waste, black line and symbol. 


\subsection{Conclusions}

Leakage testing of a representative sample of the safety-significant isolation valves for DVI in an environment that simulates the abrasive characteristics of the Hanford Tank Farms Waste Transfer System during waste feed delivery to the WTP is to be conducted (RPP-PLAN-44556, Rev. 2). The simulant test will establish the performance characteristics and verify compliance with the DSA. Proper simulant development is essential to ensure that the critical process streams characteristics are represented (NRC 2009).

A basis for evaluating DVI test simulants relative to Hanford Site waste has been described. The simulant evaluation approach is similar to the comparison of the simulant used in WRPS' SSMD small-scale mixing tests to Hanford waste (Wells et al. 2012) and simulant definition for the Tank Operations Contractor Waste Feed Delivery Mixing and Sampling Program tank performance testing (Lee et al. 2012).

Comparison of the simulants and waste characterization was made by computing 10 metrics for five primary phenomena describing valve surface abrasion due to particle interaction as well as five secondary metrics for pipeline transfer and erosion as the slurry is flowing through the piping, particle settling under conditions of no flow, and particle suspension for conditions of re-establishing flow as described below. The different metrics are considered because the dependence of these metrics on particle characteristics are different, and include:

1-5. Valve surface relative abrasive wear rate for stainless steel, nickel plating, Tefzel $^{\circledR}, \mathrm{Kynar}^{\circledR}$, and UHMWPE

6. Pipeline critical transport velocity

7. Pipeline erosion rate

8. Archimedes number

9. Settling velocity

10. Critical shear stress for erosion of non-cohesive particles.

Characterizations of the simulant and waste particles with respect to particle size, density, and hardness and valve surface hardness were described together with a summary of the uncertainties of the waste characterization. Comparison of the simulant specified in RPP-PLAN-44556, Rev. 2, relative to Hanford waste showed that the simulant is generally similar for up to $80 \%$ by volume of the composite waste characterization for metrics related to pipeline erosion, but it is not challenging with respect to DVI valve abrasive wear. As a result, the client requested an adjusted simulant be defined that matched the $75^{\text {th }}$ percentile by waste undissolved solid volume of the metrics.

An alternative DVI valve testing simulant has been designed using selected components from the RPP-PLAN-44556, Rev. 2, and Lee et al. (2012) simulants to represent the $75^{\text {th }}$ percentile by volume of characterized Hanford waste particulate based on the comparison metrics with the valve surface abrasion metrics given highest priority. The recommended simulant qualitatively matches or is more challenging than the $75^{\text {th }}$ percentile by volume waste target, and the simulant development took into account the cost and availability of potential components. The component characteristics are representative of Hanford waste particulate. 
There is a potential that garnet and/or Olivine will be introduced into the waste during retrieval operations. While either garnet or Olivine may be added to DVI test simulant (RPP-PLAN-44556, Rev. 2), it was not included in the recommended simulant designed to represent the actual waste as characterized. 


\subsection{References}

10 CFR 830, Subpart A. 2001. "Nuclear Safety Management." Subpart A, "Quality Assurance Requirements." Code of Federal Regulations, U.S. Department of Energy.

24590-QL-HC4-W000-00076-02-00003, Rev. 00A. 2008. Bechtel NQA-1 Erosion Testing Final Test Report. Dominion Engineering, Inc., R-6912-13-01, Rev. 0, Reston, Virginia.

24590-WTP-PL-ENG-06-0012, Rev. 2. 2008. Issue Response Plan for Implementation of External Flowsheet Review Team (EFRT) Recommendations - M2, Mixing Vessel Erosion. Bechtel National, Inc., Richland, Washington.

24590-WTP-RPT-RT-12-001, Rev. 0. 2012. FLUENT Newtonian Model Verification and Validation Simulant Development Basis and Initial Simulant Approach. Bechtel National, Inc., Richland, Washington.

24590-WTP-RPT-RT-12-002, Rev. 1. 2012. Simulant Qualification for Computational Fluid Dynamics Testing. Bechtel National, Inc., Richland, Washington.

24590-WTP-TSP-RT-07-006, Rev. 2. 2008. Erosion Evaluation for Pulse-Jet Mixers: Testing, Scaling, and Modeling. Bechtel National, Inc., Richland, Washington.

ASTM G75-07. 2007. Standard Test Method for Determination of Slurry Abrasivity (Miller Number) and Slurry Abrasion Response of Materials (SAR Number). ASTM International, West Conshohocken, Pennsylvania.

Camenen B. 2007. "Simple and General Formula for the Settling Velocity of Particles." Journal of Hydraulic Engineering 133(2):229-233.

CCN 132846. 2006. Comprehensive Review of the Hanford Waste Treatment Plant Flowsheet and Throughput - Assessment Conducted by an Independent Team of External Experts. Chartered by the Hanford Waste Treatment and Immobilization Plant Project at the Direction of the U.S. Department of Energy, Office of Environmental Management, Washington, D.C.

De Pellegrin DV and GW Stachowiak. 2004. "Evaluating the Role of Particle Distribution and Shape in Two-Body Abrasion by Statistical Simulation. Tribology International 37(3):255-270.

DOE Order 414.1D. 2011. “Quality Assurance.” U.S. Department of Energy, Washington, D.C.

Dwyer-Joyce RS, RS Sayles, and E Ioannides. 1994. "An Investigation into the Mechanisms of Closed Three-Body Wear.” Wear 175(1-2):133-142.

Gåhlin R and S Jacobson. 1999. "The Particle Size Effect in Abrasion Studies by Controlled Abrasive Surfaces.” Wear 224(1):118-125.

Gupta R, SN Singh, and V Sehadri. 1995. "Prediction of Uneven Wear in a Slurry Pipeline on the Basis of Measurements in a Pot Tester." Wear 184(2):169-178. 
Jacobs BEA. 2005. Design of Slurry Transport Systems. I SBN1-85166-634-6, Elsevier Science Publishers LTD, Essex, England.

Lee KP, BE Wells, PA Gauglitz, and RA Sexton. 2012. Waste Feed Delivery Mixing and Sampling Program Simulant Definition for Tank Farm Performance Testing. RPP-PLAN-51625, Rev. 0, Washington River Protection Solutions LLC, Richland, Washington.

NRC - National Research Council. 2009. Advice on the Department of Energy's Cleanup Technology Roadmap: Gaps and Bridges. Committee on Development Roadmap and Implementation of a Cleanup Technology, National Academies Press, Washington, D.C.

Oroskar AR and RM Turian. 1980. "The Critical Velocity in Pipeline Flow of Slurries." AIChE Journal 26(4):550-558.

Paphitis D. 2001. "Sediment Movement Under Unidirectional Flows: An Assessment of Empirical Threshold Curves." Coastal Engineering 43(3-4):227-245.

Richardson RCD. 1967. "The Wear of Metals by Relatively Soft Abrasives.” Wear 11(4):245-275.

RPP-PLAN-44556, Rev. 2. 2011. Simulant Test Plan for Safety Significant Isolation Valves for Double Valve Isolation. Washington River Protection Solutions LLC, Richland, Washington.

RPP-RPT-41859, Rev. 0. 2009. Safety Significant Isolation Valves for Double Valve IsolationFunctions and Requirements Evaluation Document. Washington River Protection Solutions LLC, Richland, Washington.

Shipway PH and JJ Hogg. 2007. "Wear of Bulk Ceramics in Micro-Scale Abrasion - The Role of Abrasive Shape and Hardness and its Relevance to Testing Ceramic Coatings." Wear 263(7-12):887-895.

Stachowiak G and A Batchelor. 2005. Engineering Tribology. ISBN 10 0-7506-7836-4, ButterworthHeinemann, Waltham, Massachusetts.

Weber RA. 2009. Methodology and Calculations for the Assignment of Waste Groups for the Large Underground Waste Storage Tanks at the Hanford Site. RPP-10006, Rev. 8, Washington River Protection Solutions LLC, Richland, Washington.

Wells BE, PA Gauglitz, and DR Rector. 2012. Comparison of Waste Feed Delivery Small Scale Mixing Demonstration Simulant to Hanford Waste. PNNL-20637, Rev. 2, Pacific Northwest National Laboratory, Richland, Washington.

Wells BE, DE Kurath, LA Mahoney, Y Onishi, JL Huckaby, SK Cooley, CA Burns, EC Buck, JM Tingey, RC Daniel, and KK Anderson. 2011. Hanford Waste Physical and Rheological Properties: Data and Gaps. PNNL-20646, Pacific Northwest National Laboratory, Richland Washington. 
Wells BE, MA Knight, EC Buck, SK Cooley, RC Daniel, LA Mahoney, PA Meyer, AP Poloski, JM Tingey, WS Callaway III, GA Cooke, ME Johnson, MG Thien, DJ Washenfelder, JJ Davis, MN Hall, GL Smith, SL Thomson, and Y Onishi. 2007. Estimate of Hanford Waste Insoluble Solid Particle Size and Density Distribution. PNWD-3824 (WTP-RPT-153, Rev. 0), Battelle-Pacific Northwest Division, Richland, Washington. 

PNNL-22121

DVI-RPT-0001, Rev. 0

\section{Distribution}

No. of

Copies

1 DOE Office of River Protection

JP Harris

H6-60

12 Washington River Protection Solutions

LLC

DG Baide

DM Cato

JK Engeman

PA Gagnon

JE Geary

RE Gregory

JM Grigsby

SJ Harrington

DC Larsen

JG Reynolds

TL Sams

DJ Washenfelder
$\mathrm{R} 3-26$
$\mathrm{R} 2-58$

R3-26

R3-26

R3-26

S7-68

S7-90

R2-58

H3-20

R2-58

R2-52

R2-53
No. of

Copies

7 Pacific Northwest National Laboratory

HE Adkins

K7-15

PA Bredt

K9-09

CA Burns

P7-25

CW Enderlin

K7-15

J Jenks

K7-15

LM Peurrung

K9-09

BE Wells

K7-15

Distr.1 




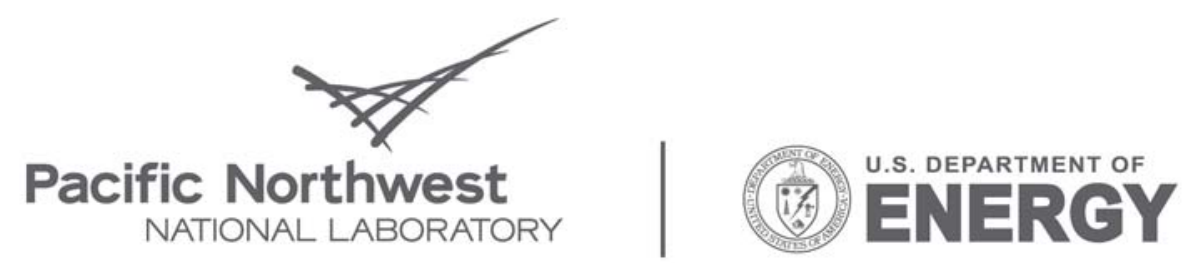

Proudly Operated by Battelle Since 1965

902 Battelle Boulevard

P.O. Box 999

Richland, WA 99352

1-888-375-PNNL (7665)

www.pnl.gov 